Western University

Scholarship@Western

Civil and Environmental Engineering

Civil and Environmental Engineering

Publications

Department

2017

\title{
Analysis of reinforced concrete beams strengthened using concrete jackets
}

M. Monir A. Alhadid

Western University

Maged Youssef

youssef@uwo.ca

Follow this and additional works at: https://ir.lib.uwo.ca/civilpub

Part of the Civil and Environmental Engineering Commons

Citation of this paper:

Alhadid, M. Monir A. and Youssef, Maged, "Analysis of reinforced concrete beams strengthened using concrete jackets" (2017). Civil and Environmental Engineering Publications. 179.

https://ir.lib.uwo.ca/civilpub/179 


\section{Analysis of Reinforced Concrete Beams Strengthened using Concrete Jackets}

2

3

4 5

6 7
M. Monir A. Alhadid ${ }^{1}$, Maged A. Youssef, P.Eng. ${ }^{2}$

${ }^{1}$ PhD Candidate, E-mail: majjanal@uwo.ca, ${ }^{2}$ Professor, E-mail: youssef@uwo.ca

Department of Civil and Environmental Engineering, Western University, London, ON, Canada N6A 5B9

\section{Abstract:}

Analysis of jacketed Reinforced Concrete $(\mathrm{RC})$ beams considering the interfacial slip effect is a complicated problem. In the current practice, slip is neglected in the analysis and monolithic behavior is assumed in the jacketed section resulting in higher estimates of stiffness and/or capacity. Engineers need simplified yet robust tools to predict the actual behavior of jacketed RC beams. This paper provides a simplified method to analyze jacketed RC beams taking into account the interfacial slip distribution and the actual nonlinear behavior of both concrete and steel. An iterative calculation algorithm is developed to determine the moment-curvature and load-deflection curves of the jacketed beams. The developed method provides an evaluation of the slip and shear stress distributions, which allow assessing the influence of surface roughness conditions. The developed method is utilized to conduct an extensive parametric study, which resulted into modification factors to calculate the capacity and deformations of strengthened beams while accounting for interfacial slip.

Keywords: Reinforced Concrete; Jacketing; Slip; Interfacial Behavior; Monolithic Factors; Inelasticity; Flexure. 


\section{Introduction}

Several reasons necessitate rehabilitating a Reinforced Concrete (RC) structure including: new safety requirements, a change of structure occupancy, an incorrect design calculations and/or degradation of materials with time. Flexural strengthening of RC beams results in increasing their capacity and stiffness to accommodate certain design requirements. One of the most commonly used strengthening techniques for RC beams involves the application of RC jackets at either one side or three sides of their sections. The added concrete layers are usually reinforced with longitudinal steel bars, stirrups, welded wire mesh or various kinds of fibrous materials. The behavior of RC members strengthened with RC jackets was investigated experimentally by many researchers [1-10].

Composite beams have been used in construction since time immemorial in the form of layered timber planks glued or packed together with ropes to create one entity. The efficiency of such structural elements relies chiefly on the ability of the sliding surfaces to transfer the generated shear stresses [11]. The 1966 Canadian [12] and American [13] standards included provisions for the concrete-to-concrete interfacial behavior in view of shear-friction theory. According to this theory, the horizontal shear strength along the interface depends on four main parameters; namely, the concrete-compressive strength, the vertical-pressure component at the interface, the ratio of transverse reinforcement crossing the interface, and the roughness of the underlying-concrete surface [14]. In many design practices, full bond between the existing and the added concrete layers in jacketed RC beams is assumed. The accuracy of this assumption depends on the loading type, the interface-shear-plane area, the surface roughness and the layout of the attached concrete jacket. However, in typical constructions, a relative slip is expected between the new and old concrete layers, which may result in separation of the two surfaces [15] and will influence the capacity and stiffness of a jacketed beam. 
44 The following sections summarize the developed calculation algorithm for estimating the behavior of $45 \mathrm{RC}$ beams jacketed with concrete. The material and interfacial mechanical behaviors are estimated from relevant models found in literature. Subsequently, the developed algorithm is validated in view of relevant experimental studies. The model is utilized to investigate the effects of interfacial friction coefficient, material properties and geometrical characteristics on the flexural behavior of the jacketed beams. Slip modification factors are proposed to allow engineers to estimate the critical design variables.

\section{Material Models}

Scott et al.'s model [16] is adopted to model the concrete in compression as it provides a robust yet simple expression to describe its stress-strain behavior. Concrete is assumed to fail when the crushing strain reaches a value of 0.0035 [12]. Concrete is assumed to carry tensile stresses up to the cracking point beyond which the tensile capacity of concrete drops to zero.

The steel reinforcement monotonic stress-strain relationship is expressed according to the model reported by Karthik and Mander [17] in view of the general formula proposed by Ramberg and Osgood [18]. It conveniently combines the initial elastic response, yield plateau and strain hardening stages in a single rigorous form to model the actual behavior of steel bars. The value of the strain hardening strain $\left(\varepsilon_{s h}\right)$ is set equal to the yield strain $\left(\varepsilon_{y}\right)$ and the strain hardening modulus $\left(E_{s h}\right)$ is taken as $1 \%$ of the 61 Young's modulus of elasticity $\left(E_{S}\right)$.

62

\section{Typical Strain and Stress Distributions in Jacketed RC Beams}

Simply supported beams jacketed from one side and three sides are considered in the analysis.

The concrete jacket in both cases extends between the two supports along the entire beam. The cross- 
67 section, $b_{c}$ is the interface width, $h_{J}$ is the thickness of the attached concrete jacket, $d_{c}$ is the effective

68 depth of the tension core reinforcement, $d_{c}^{\prime}$ is the effective depth of the compression core reinforcement,

$69 A_{s, c}$ is the area of the tension core reinforcement, $A_{s, c}^{\prime}$ is the area of the compression core reinforcement,

70 and $A_{s, J}$ is the area of the tension jacket reinforcement. The corresponding strain profile is illustrated in

71 Fig. 1(b) where $\varepsilon_{c, \text { top }}$ and $\varepsilon_{c, \text { bot }}$ are the strains at the top and bottom fibers of the original beam; $\varepsilon_{J, t o p}$ and

$72 \varepsilon_{J, b o t}$ are the strains at the top and bottom fibers of the attached concrete jacket; $\varepsilon_{s, t o p}, \varepsilon_{s, b o t}$ and $\varepsilon_{s, J}$ are the

73 strains developed in the top core reinforcement, bottom core reinforcement and jacket reinforcement,

74 respectively. $\Delta \varepsilon$ is the slip strain, which represents the drop in strain at the interface caused by the relative

75 slip between the two surfaces. The resulting stress distribution at an arbitrary section located at a distance

76 of $(x)$ from the support is shown in Fig. 1(c). In this figure, $f_{c, c}$ and $f_{c, J}$ represent the stress distribution

77 in the concrete core and jacket, respectively; $f_{S, c}, f_{s, c}^{\prime}$ and $f_{s, J}$ represent the stress generated in the core

78 top reinforcement, core bottom reinforcement and jacket reinforcement, respectively; and $\tau(x)$ is the shear

79 stress distribution along the interface from the support to the section under consideration. If the beam is

80 jacketed from three sides, only the effect of slip along the horizontal interface is taken into account. The

81 inaccuracy that may be caused by this assumption is minor and can be ignored [19] as slip becomes less

82 remarkable closer to the neutral axis. For the 3-sides jacketing scheme, an additional term must be added

83 to the stress distribution shown in Fig. 1(c) to account for the compressive stress acting on the two vertical

84 sides of the jacket.

85

86 4. Interfacial Shear Stress $(\tau)$ and Slip $(S)$ Relationship

Interfacial shear-slip models are generally expressed as the summation of concrete contribution

(i.e. adhesion, aggregate interlock and friction) and dowel action owing to any transverse reinforcement

crossing the interface. The model proposed by Tassios and Vintzeleou [22] to determine the concrete 
contribution $\left(v_{c}\right)$ in transferring the shear along a contact plane is adopted. The frictional force generated

91 between the two substrates depends on the surface roughness and the applied normal pressure due to the

92 reinforcing bars crossing the interface as depicted in Fig. 2. As the relative slip $(S)$ between the existing

93 concrete layer and the attached jacket increases, some overriding deformations occur due to the uneven

94 surfaces causing them to move apart from each other. This lateral movement generates pullout forces in

95 the vertical steel bars that in turn produce compressive forces on the concrete to maintain equilibrium

96 along the interface. The steel bars (dowels) also provide horizontal force components that contribute

97 directly to the interfacial shear resistance.

98 Tassios and Vintzeleou [22] empirical model is presented in terms of the lateral slip $(S)$, ultimate 99 slip value at the onset of frictional mechanism failure $\left(S_{c u}\right)$ and ultimate frictional capacity of the interface $100 \quad\left(v_{c u}\right)$ as expressed by Equations 1 and 2.

$$
v_{c}(S)=\left\{\begin{array}{cc}
1.14\left(v_{c u}\right)\left(\frac{S}{S_{c u}}\right)^{\left(\frac{1}{3}\right)} & ,\left(\frac{S}{S_{c u}}\right) \leq 0.5 \\
\left(v_{c u}\right)\left[0.81+0.19\left(\frac{S}{S_{c u}}\right)\right], & \left(\frac{S}{S_{c u}}\right)>0.5 \\
v_{c u}=\mu\left(f_{c}^{\prime 2} \rho_{s} f_{s}\right)^{\left(\frac{1}{3}\right)}
\end{array}\right.
$$

101 where $\mu$ is the coefficient of friction at the interface, $\rho_{s}$ is the reinforcement ratio of the bars crossing the 102 interface and $f_{s}$ is the corresponding tensile stress developed in these bars as given in Equation 3.

$$
f_{s}=\left(\frac{0.3 S^{\left(\frac{2}{3}\right)} E_{s} f_{c}^{\prime}}{D_{b}}\right) \leq f_{y}
$$

The resultant dowel force $\left(V_{D}\right)$ is expressed as a function of the lateral slip between the two 104 concrete surfaces, studs' diameter $\left(D_{b}\right)$ and the ultimate dowel force $\left(V_{D u}\right)$ given by Equations 4 and 5. 


$$
S=\left\{\begin{array}{cc}
0.012\left(\frac{V_{D}(S)}{V_{D u}}\right) & , S \leq 0.006 D_{b} \\
0.006 D_{b}+0.088 D_{b}\left[\left(\frac{V_{D}(S)}{V_{D u}}\right)^{4}-0.5\left(\frac{V_{D}(S)}{V_{D u}}\right)^{3}\right], & \frac{V_{D}(S)}{V_{D u}} \geq 0.5 \\
V_{D u}=1.3 D_{b}^{2} \sqrt{f_{c}^{\prime} f_{y}} &
\end{array}\right.
$$

\section{Interfacial Shear Stress $(\tau)$ and Slip Strain $(\Delta \varepsilon)$ Relationships}

Equation 6. This assumption was validated through performing a numerical analysis aiming at defining the shape of the shear stress distribution along the interface [15].

$$
\tau=A x^{3}+B
$$

Slip, and consequently shear stress, reach their maximum value at the support and fade away as

111 they approach the maximum bending moment section (i.e. beam mid-span). The proportion of the average shear stress $\left(\tau_{\text {avg }}\right)$ distribution from support to mid-span relative to its maximum value $\left(\tau_{\max }\right)$ are related by a factor $\gamma_{1}$ (i.e. $\left.\gamma_{1}=\tau_{a v g} / \tau_{\max }\right)$. The average slip strain $\left(\Delta \varepsilon_{a v g}\right)$ is defined as a proportion of its maximum value $\left(\Delta \varepsilon_{\max }\right)$ by a factor of $\gamma_{2}$ (i.e. $\left.\gamma_{2}=\Delta \varepsilon_{a v g} / \Delta \varepsilon_{\max }\right)$. The maximum $\operatorname{sip}\left(S_{\max }\right)$ is determined as the product of the distance from support to mid-span section $(L / 2)$ and the average slip strain $\left(\Delta \varepsilon_{a v g}\right)$ 116 along that same distance. At any applied load increment, the average value of interfacial shear stress 117 ( $\left.\tau_{\text {avg }}\right)$ can be obtained by assuming a direct relationship with the maximum slip strain $\left(\Delta \varepsilon_{\max }\right)$ value located 118 at the beam mid-span $[5,11,12]$. From the above discussion, average shear stress can be expressed in terms of the factors $\gamma_{1}$ and $\gamma_{2}$ according to Equation 7.

$$
\tau_{\text {avg }}=\gamma_{1} \tau_{\max }=\gamma_{1}\left[k_{S} S_{\text {max }}\right]=\gamma_{1}\left[k_{s}\left(\Delta \varepsilon_{\text {avg }} \frac{L}{2}\right)\right]=\gamma_{1}\left[k_{s}\left(\gamma_{2} \Delta \varepsilon_{\max } \frac{L}{2}\right)\right]
$$

The global interfacial slip coefficient $(K)$ is defined by Equation 8 . 


$$
K=k_{s} \gamma\left(\frac{L}{2}\right)
$$

121 where $k_{s}$ is the secant interfacial stiffness $\left(\mathrm{N} / \mathrm{mm}^{3}\right)$ and $\gamma$ is the product of the factors $\gamma_{1}$ and $\gamma_{2}$. By

122 combining Equations 7 and 8, $\tau_{\text {avg }}$ can be expressed by Equation 9.

$$
\tau_{\text {avg }}=K \Delta \varepsilon_{\max }
$$

To evaluate the coefficients $(A)$ and $(B)$ in Equation 6, two boundary conditions are determined.

124 The first one is assigning the interfacial shear stress $(\tau)$ a value of zero at the beam mid-span and the

125 other one is setting the average shear stress resulting from the distribution provided by Equation 6 as $\tau_{a v g}$ defined in Equation 9. Solving Equation 6 for the coefficients $(A)$ and $(B)$ and integrating it with respect to $(x)$ provides the corresponding interfacial shear force $\left(F_{\tau}\right)$ at any section at a distance $(x)$ from the support as expressed by Equation 10.

$$
F_{\tau}=(b)\left[\left(\frac{4 \tau_{a v g}}{3}\right)(x)-\left(\frac{\tau_{a v g}}{3\left(\frac{L}{2}\right)^{3}}\right)\left(x^{4}\right)\right]
$$

\section{Proposed Calculation Algorithm}

132 the interface and to determine the moment-curvature $(M-\varphi)$ relationship at different segments along the jacketed beam. The proposed model considers the full non-linear characteristic of the jacketed RC beams

134 taking into account both the elastic and post-yield behaviors. This allows the determination of the 135 capacity and deformation behavior of ductile members rather than limiting the analysis to brittle [19] or 136 linear elastic sections [20,21]. The influence of interfacial slip on the flexural behavior of the jacketed

137 beams is modeled by modifying Tsioulou and Dritsos [15] procedure that was derived based on Eurocode 138 [23] expressions. According to their model, the beam is considered as one entity and integrations are 
139 performed to estimate the slip and shear stress distributions along the interface. The effect of slip would

140 thus be reflected through obtaining a $M-\varphi$ diagram that describes the flexural behavior of any section

141 along the beam. In the current proposed method, the beam is divided into multiple segments, Fig. 3, and

142 a unique $M-\varphi$ diagram is obtained for each segment using sectional analysis technique [24].

143 Each point on the $M-\varphi$ diagrams (at each segment) can be obtained through an iterative procedure

144 to incorporate the slip strain $(\Delta \varepsilon)$ distribution in the analysis at each beam segment. The kinematic and 145 compatibility conditions are considered in view of the corresponding material stress-strain relationships.

146 Assumptions that are made in the developed procedure are: (1) the cross section remains plane, (2) perfect

147 bond exists between the steel reinforcement and the surrounding concrete material, (3) the failure

148 criterion of the composite beam is defined by crushing of the extreme compression fiber, and (4) the

149 original RC beam and the added concrete layer are considered to deform by the same curvature 150 throughout the beam length.

151 The proposed calculation algorithm comprises two main stages. In the first one, the beam is

152 divided into a number of segments having a maximum length of $50 \mathrm{~mm}$ each which was found to enhance

153 the accuracy based on a preliminary sensitivity analysis as illustrated in Fig. 3. Then, an iterative sectional

154 analysis procedure is performed at different load increments at the mid-span section only to obtain the

155 maximum slip strain $\left(\Delta \varepsilon_{\max }\right)$ at that section and the corresponding slip strain $(\Delta \varepsilon)$ and slip $(S)$ at all other

156 beam segments. In the second stage, sectional analysis is conducted directly at the other sections taking

157 into account the $\Delta \varepsilon$ evaluated from the first analysis phase for each beam segment. Details about the

158 developed method are given below.

159

160

161 


\subsection{Iterations at Mid-Span Section}

Combining the sectional analysis method [24] with the interfacial slip model [22] at different

164 segments along a jacketed beam provides the base for the developed algorithm as illustrated in the

165 flowcharts in Figs. 4 through 6. An iterative sectional analysis is carried out at the beam mid-span section

166 to determine the maximum slip strain $\left(\Delta \varepsilon_{\max }\right)$ value at various load increments up to failure. The

167 composite section is first divided into multiple discrete strips having a maximum height of $2 \mathrm{~mm}$ for better accuracy. At every load step, an incremental curvature $(\Delta \varphi)$ is applied and the strain at each strip in both the concrete core and the jacket is calculated based on its location from the centroid of the jacketed section. Each curvature increment comprises the following steps:

(1) Assume a value of the secant interfacial stiffness $\left(k_{s}\right)$.

(2) Assume a value of the shear stress distribution factor $(\gamma)$ shown in Equation 8.

173 (3) Calculate the global interfacial slip coefficient $(K)$ defined by Equation 8.

174 (4) For the total curvature $(\varphi)$ of the current step, apply two equilibrium conditions at the mid-span section; namely, equilibrium between the internal forces at the section, and equilibrium between the resultant axial forces at one side of the interface and the resultant shear force $\left(F_{\tau}\right)$ acting along the interface. The interfacial shear force can be obtained from Equation 10. The outcomes of this step are the moment $(M)$ and maximum slip strain $\left(\Delta \varepsilon_{\max }\right)$ at beam mid-span section corresponding to the current 179 curvature value $(\varphi)$.

180 (5) Determine the load value $(P)$, which produces a moment equal to the value obtained from step 4 at 181 the beam mid-span section. This load is then used to determine the bending moment distribution along 182 the beam. For each beam segment, Fig. 3, an average bending moment value is considered. 
(6) Determine the slip strain $(\Delta \varepsilon)$ at each beam segment from Equation 11 in which $i$ is the load step

184 number, $j$ is the segment number and $m$ is the load step number that produces a bending moment in the 185 mid-span segment equals to the moment applied at segment $j$.

$$
\Delta \varepsilon_{(i, j)}=\Delta \varepsilon_{(m, 1)}\left(\frac{x_{j}}{(L / 2)}\right)
$$

186 (7) Once the slip strain $(\Delta \varepsilon)$ distribution along the interface is established, both the slip $(S)$ and the shear

187 stress $(\tau)$ distributions are obtained using the developed equations 12 and 13, respectively.

$$
\begin{gathered}
S_{(i, j)}=\sum_{n=1}^{n=j}\left[\left(\Delta \varepsilon_{(i, n)}\right)\left(x_{j}\right)\right] \\
\tau_{(i, j)}=k_{S} S_{(i, j)}
\end{gathered}
$$

188 (8) Calculate the shear stress distribution factor $(\gamma)$, shown in Equation 8, and compare it to the initially assumed value. The analysis continues if they are equal, otherwise the whole procedure is repeated with 190 the new calculated value.

(9) Determine the secant interfacial stiffness $\left(k_{s}\right)$ value from Tassios and Vintzeleou [22] shear stress-

192 slip model in terms of $\tau_{\max }$ and compare it to the previously assumed value. The analysis continues if 193 they are equal, otherwise the whole procedure is repeated with the new obtained value.

\subsection{Obtaining Moment-Curvature Relationship at Other Beam Segments}

Having obtained the slip strain $(\Delta \varepsilon)$ at each beam segment, a unique $M-\varphi$ diagram is determined using sectional analysis method. Then, deflection at the mid-span point of the simply supported beam is determined using the moment-area method. If the beams were subjected to initial loading prior to 199 jacketing, then a preliminary sectional analysis on the unjacketed sections has to be carried out first to 200 obtain the resulting $M-\varphi$ curve and strain profile at each beam segment. These diagrams will then be 
202 different loading stages before and after jacketing. The calculation algorithm according to the 203 aforementioned procedure and the flow charts in Figs. 4 through 6 is illustrated in the Appendix 204 considering beam B-3 in Table 1.

\section{Validation}

The capability of the present model to predict the flexural behavior of jacketed RC beams is validated in view of the experimental results obtained by Chalioris and Pourzitidis [1], Chalioris et al. 209 [2], Martinola et al. [3], Hussein et al. [4] and Shehata et al. [5]. The geometrical mechanical properties 210 of the examined specimens are detailed in Table 2. In general, the proposed model is found to be in a 211 very good agreement with the experimental results as shown in Table 2 and Figs. 7 through 9.

\subsection{Chalioris and Pourzitidis [1]}

The influence of applying self-compacting concrete (SCC) jackets on the flexural behavior of RC beams was investigated by Chalioris and Pourzitidis [1]. The experimental program commenced by applying monotonic two point concentrated loads on the RC beams to cause some cracks. The load was then removed and a self-compacting concrete (SCC) jacket was applied from three sides to strengthen the cracked beams. The load-deflection curves for beams B2-J and B4-J were obtained analytically and compared to the experimental results as shown in Figs. 7(a) and 7(b), respectively. The capability of the model to capture the full deformation behavior is proved by the small error in the yield load, ultimate load and elastic stiffness as indicated in Table 2. 


\subsection{Chalioris et al. [2]}

In another relevant study, Chalioris et al. [2] further investigated the flexural performance of simply supported RC beams jacketed with SCC jackets from three sides. Beam B1-M having the properties shown in Table 2 is considered for validation. A comparison between the experimental and analytical moment-deflection relationship of the examined beam is shown in Fig. 7(c). Again, the model is found to well predict the actual deformation behavior at different load values. The error associated with yield and ultimate loads is acceptable as indicated in Table 2 . The relatively high stiffness obtained from the analytical model can be justified by the presence of initial cracks in the original beam before jacketing.

\subsection{Martinola et al. [3]}

The flexural behavior of simply supported beams jacketed with high performance fiber reinforced concrete was investigated experimentally by Martinola et al. [3]. The jacket material was cast of selfleveling mortar with embedded steel microfibers having a diameter of $0.18 \mathrm{~mm}$ and length of $12 \mathrm{~mm}$.

The actual material stress-strain behavior was obtained by conducting a direct tensile test on dog-bone specimens and two-point bending tests on unreinforced prisms. The beams were subjected to a displacement controlled load until crushing of concrete occurred. The resulting load-deflection is shown in Fig. 7(d) along with the analytically obtained ones assuming a partially composite action. The sudden drop after reaching the peak point is justified by the full cracking of the jacketing material. As illustrated in Table 2, there is an excellent agreement between the analytical and experimental results in the ultimate capacity, yield load and elastic stiffness. 


\subsection{Hussein et al. [4]}

The work carried out by Hussein et al. [4] examined the effectiveness of providing ultrahigh performance strain hardening cementitious composite (UHP-SHCC) layer with or without a small amount of steel reinforcement. The role of the steel reinforcement is to counteract the stiffness 252 degradation of UHP-SHCC strengthening layer, caused by cracking, and consequently eliminates the observed early strain localization. The overall deformation behavior of beams B-U-0, B-U-1 and B-U-2 are investigated analytically and compared to the experimental results as indicated in Fig. 8. The loaddeflection curves obtained analytically considering slip effect matches the experimental curves with small percent error in both the elastic and inelastic regions as indicated in Table 2.

\subsection{Shehata et al. [5]}

Shehata el al. [5] studied the influence of various jacketing configurations on the load-deflection and slip behaviors of RC jacketed beams. Beams V2A and V3A are considered in the validation as they vary in the amount of original main steel and the percentage of the added steel in the jacket for flexural strengthening. The beams were loaded at their mid-span by means of controlled hydraulic jack. The experimental study started by loading the unjacketed beams until the strains in their flexural steel reached a value close to $2 \%$. The beams were then unloaded, jacketed and then tested until crushing of concrete took place. A Very good agreement between the analytical and experimental load-deflection curves are shown in Fig. 9(a) for beams V2A and V3A. The maximum error in the elastic flexural stiffness and capacity in both beams is small as shown in Table 2. The maximum slip recorded at different loading stages for beam V3A was recorded experimentally and compared to the analytical results as shown in Fig. 9(b). The slip in the analytical model commences at the onset of load but with an acceptable 270 difference from the actual slip. 


\section{Parametric Study}

The main parameters are the concrete compressive strength $\left(f_{c}^{\prime}\right)$, steel yield strength $\left(f_{y}\right)$, coefficient of friction at the interface $(\mu)$, existing beam depth $\left(h_{c}\right)$, concrete jacket thickness $\left(h_{J}\right)$, beam width $\left(b_{c}\right)$ and beam span $(L)$. The values of the chosen parameters are set based on the practical 275 considerations in the design of typical RC buildings. The mechanical properties for concrete are defined 276 in terms of concrete compressive strength as $25 \mathrm{MPa}, 30 \mathrm{MPa}$ and $35 \mathrm{MPa}$; and defined for steel in terms 277 of yield strength as $300 \mathrm{MPa}, 400 \mathrm{MPa}$ and $500 \mathrm{MPa}$. In practice, concrete jacket is made from similar 278 or stronger materials than the original beam. Thus, the mechanical properties of both the concrete core and the attached jacket are assumed to be the same in the analysis. The coefficient of friction is assumed to range between 0.4 for smooth concrete surface and 1.4 for intentionally highly roughened concrete in 281 increments of 0.2. The beams' cross-sectional dimensions are defined with reference to the unjacketed 282 beam height $(300 \mathrm{~mm}, 450 \mathrm{~mm}$ and $600 \mathrm{~mm})$, jacket thickness $(100 \mathrm{~mm}, 150 \mathrm{~mm}$ and $200 \mathrm{~mm})$, unjacketed beam width (200 mm, $300 \mathrm{~mm}$ and $400 \mathrm{~mm})$, and span $(3 \mathrm{~m}, 4 \mathrm{~m}$ and $5 \mathrm{~m})$. The main steel 284 reinforcement in the concrete core is set as 0.01 and 0.02 . The amount of jacket reinforcement is decided 285 based on the maximum practical spacing for $10 \mathrm{M}$ bars placed in one layer to resist flexural loads 286 according to CSA A23.3-14 [12]. The compression steel reinforcement is fixed at 2- $\phi 6 \mathrm{~mm}$ bars in all beams. Two jacketing schemes are adopted in the analysis. In the first one, the beams are jacketed at their soffits only; whereas in the second configuration, the beams are jacketed from three sides forming a U-shape. Therefore, for each jacketing scheme, a total of 10,206 cases are considered in the analysis. The following discussion refers to the beam sections in Table 1 for the cases involving $f_{c}^{\prime}=30 \mathrm{MPa}, f_{y}=$ $400 \mathrm{MPa}$ and $\mu=0.4$ unless otherwise specified. 


\section{Flexural Behavior of the Jacketed Beams}

\subsection{Effect of Beam Width $\left(b_{c}\right)$}

The effect of varying beam width $\left(b_{c}\right)$ on the $M-\varphi$ relationship for simply supported beam jacketed from 1 side and 3 sides is shown in Fig. 10. Beams B-3, B-12 and B-21 are considered for comparison. Increasing $b_{c}$ increases the beam's elastic stiffness and capacity. The two sudden changes in the slope indicate the jacket reinforcement yielding followed by core steel bars yielding. The elastic stiffness decreases when slip is considered and the extent of this reduction has an inverse relationship with the beam width. Increasing the beam width increases the contact surface between the concrete core and the attached jacket. The relative slip between the two surfaces results in a strain reduction $(\Delta \varepsilon)$ in the jacket layer that delays the onset of jacket reinforcement yielding. Once jacket yielding is reached, the $M-\varphi$ behavior becomes identical to the one obtained assuming a full composite section. The behavior of the beam jacketed from 3 sides exhibits the same behavior of the one jacketed from 1 side. However, the extent of stiffness reduction is less significant due to the larger contact area provided by the U-shape jacket.

When slip is considered in the analysis, the $M-\varphi$ diagram varies at each segment in the beam as discussed previously. The load-deflection curve has an advantage in capturing the full behavior along the entire beam span making it easier to track the overall flexural behavior as shown in Fig. 11. For initially unloaded one-side jacketed beams, increasing the beam width is found to increase its capacity by about $25 \%$ as illustrated in Fig. 11(a). Any increase in core width for beams jacketed from one side results in a more significant increase in the capacity compared to the beams jacketed from three sides. Also, the overall drop in the initial flexural stiffness decreases as the core width increases for the examined range. The stiffness reduction is more pronounced in the beams jacketed from three sides since larger total jacket width is considered in the analysis. The load-deflection curves for the beams jacketed 
317 from one side and initially subjected to $25 \%$ of their unjacketed capacities are presented in Fig. 11(b).

318 Adding extra reinforced concrete layer in the jacket results in a significant increase in the elastic stiffness

319 by more than $50 \%$. All beams failed by concrete crushing at the same ultimate load regardless of the 320 initial load they were subjected to prior to jacketing. Initially loaded beams experience more ductility as 321 the additional jacket steel bars were unstressed at the moment the partial interaction between the core 322 and the jacket commenced. The influence of slip on reducing the flexural stiffness of the jacketed beams 323 becomes less pronounced when jacketing takes place at higher initial loads. This is caused by the 324 relatively low stresses within the jacket compared to the ones generated in the existing beam due to the 325 initial load.

326 In the subsequent discussions, influence of slip on the moment-curvature and load-deflection 327 relationships has a similar trend to the curves shown in Figs. 10 and 11 but with different magnitudes, 328 respectively. Thus, repetition of the specific curves for each parameter is not shown but can be understood 329 in view of Figs. 10 and 11.

\subsection{Effect of Jacket Thickness $\left(h_{J}\right)$}

Increasing jacket thickness has a direct impact on both the yield and ultimate capacities of the strengthened beams owing to the increase in cross-sectional area and lever arm to the steel bars within the jacket. This rise is more pronounced in beams jacketed from three sides since part of the jacket extends above the neutral axis and contributes more in resisting the compressive stresses. Using the Ushape jacket increases the flexural ductility up to $18 \%$ for the considered range of jacket thicknesses. Doubling the jacket thickness from $100 \mathrm{~mm}$ to $200 \mathrm{~mm}$ results in increasing the capacity by just over $15 \%$ when the beam is jacketed from its soffit and by around $53 \%$ when it is jacketed from three sides. In all sections, larger drop in the elastic stiffness is observed as the jacket thickness increases. However, 
340 the reduction becomes less significant and almost constant if the beam is jacketed from three sides. For 341 initially loaded beams, adding the reinforced concrete layers at a later stage results in increased overall 342 ductility while maintaining the same ultimate capacity. Also, the load-deflection curves considering the 343 interfacial slip tend to approach the ones obtained assuming monolithic sections for the same 344 aforementioned reasons.

\subsection{Effect of Existing Beam Height $\left(h_{c}\right)$}

The variation of concrete core height is discussed in view of beams B-3, B-6 and B-9. Crosssectional height plays a major role in increasing the concrete area subjected to compression. It also increases the lever arm of not only the jacket steel reinforcement, but also the main core steel bars. This results in a significant increase in both the elastic stiffness and the ultimate strength while reducing 351 ductility. By doubling the core height from $300 \mathrm{~mm}$ to $600 \mathrm{~mm}$, the initial stiffness increase by about 352 four folds and approximately three times for the beams jacketed from one side and three sides, 353 respectively. The stiffness reduction due to slip is found to decrease slightly as the concrete core height 354 increases for both jacketing configurations. For initially loaded beams, the flexural behavior of the 355 jacketed beams approaches the monolithic assumption as the initial load increases. Therefore, slip 356 influence can be ignored if jacketing takes place while the beam is subjected to a significant percentage 357 of its ultimate capacity.

\subsection{Effect of Beam Span (L)}

The effect of changing the span on the flexural behavior of jacketed beams is presented in view

361 of beams B-3, B-30 and B-57. If a monolithic interaction is assumed, then the beams' flexural behavior 362 depends merely on the section geometry and does not vary regardless of the span. However, if partial 
363 interaction is considered in the analysis, then the span length becomes a major parameter in determining 364 the actual $M-\varphi$ behavior of the jacketed beams. Increasing the beam span results in a consequent reduction 365 in the ultimate capacity but a significant increase in ductility. As the span increases, the contact area 366 between the concrete core and the attached jacket also increases resulting in higher interfacial frictional 367 forces and consequently lower relative displacement between the two surfaces. Increasing the span from $3683 \mathrm{~m}$ to $5 \mathrm{~m}$ results in a drop of the initial stiffness by about $40 \%$ and $60 \%$ for the beams jacketed at their 369 soffit and three sides, respectively. It is worth mentioning that increasing the span becomes more 370 significant as the jacket width increases. This causes the beams surrounded by jacket from three surfaces 371 to exhibit less initial stiffness reduction relative to the ones jacketed from one side only. Also, the 372 stiffness reduction rate decreases as the span increases as indicated by the $13 \%, 8 \%$ and $5 \%$ drop in initial 373 stiffness for the one-side jacketed beams B-3, B-30 and B-57, respectively. The same observation is 374 shown for the other jacketing scheme but to a less extent as indicated by the $9 \%, 6 \%$ and $4 \%$ reduction 375 in initial stiffness for the same beams, respectively. Applying the jacket once the existing beam reaches $37625 \%$ or $50 \%$ of its ultimate capacity reduces the influence of interfacial slip on the flexural behavior of 377 the jacketed beams.

378 All of the examined beams experience flexural mode of failure as sufficient stirrups are provided 379 to eliminate premature shear failure. Moment-shear interaction along the span is examined in view of 380 Russo et al. [25] proposed expressions for $M_{u} / M_{f l}$, where $M_{u}$ is the flexural capacity including shear 381 influence and $M_{f l}$ is the pure flexural capacity. For all of the examined beams, it was found that decreasing 382 the shear span to depth ratio $\left(L_{s} / d\right)$ results in a more pronounced reduction in flexural capacity. For 383 instance, a drop of about $19 \%$ and $27 \%$ in the flexural capacity of beam B-3 subjected to a mid-span 384 concentrated load and uniform load, respectively. On the other hand, the change in capacity in beam B- 
57 is less significant due to the longer span. The same conclusion was obtained by Chalioris and 386 Pourzitidis [1] who experimentally examined the behavior of jacketed RC beams with various $L_{s} / d$ ratios.

\subsection{Effect of Concrete Compressive Strength $\left(f_{c}^{\prime}\right)$}

Increasing the concrete compressive strength increases the stiffness and capacity of the jacketed

beams for both 1 side and 3 sides jacketing configurations. However, its influence is found to be more

pronounced in the latter case. This is justified by the greater area of concrete subjected to compression

that results in higher stiffness and capacity. Considering beam B-1, a 12\% increase in capacity for the Ushape jacketed beam is shown compared to the $5 \%$ for the other jacketing scheme. In addition, flexural

ductility is shown to have a direct relationship with concrete compressive strength and jacketing scheme.

For the same concrete grade, ductility is more remarkable when the beam is jacketed from three-sides.

Furthermore, slip reduction rate within the elastic range decreases as the compressive strength increases

because of the larger surface friction provided at the interface corresponding to the stronger concrete.

This explains the $11 \%$ and $5 \%$ drop in the initial stiffness for the beam cast of concrete grades $25 \mathrm{MPa}$ and $35 \mathrm{MPa}$, respectively.

\subsection{Effect of Steel Yield Strength $\left(f_{y}\right)$}

An inverse relationship between the steel grade and the ductility of the entire beam is detected due to the fact that the ductility of steel bars decreases as their ultimate strength increases. For the same steel grade, it is found that the ultimate curvatures the beams reached are almost the same regardless of the jacketing scheme. The initial stiffness for all beams with the same jacketing configuration is identical since all steel bars share the same elastic stiffness. The stress in all steel bars is related to the modulus of 
408 initial stiffness between the beams reinforced with steel bars of different grades is not substantial. This 409 observation is explained by knowing that once the steel bars in both the jacket and the core have been 410 yielded, the resistance becomes almost identical to the beam behaving monolithically. Thus, the main 411 reduction in stiffness is witnessed in the elastic zone.

\section{10. Interfacial Slip Behavior}

414 The partial interaction between the existing concrete beam and the attached jacket is better 415 understood in view of the slip strain, slip and horizontal shear distribution along the interface. The 416 following discussion is presented in view of beam B-5 whose geometrical properties are shown in Table 4171 with $f_{c}^{\prime}=30 \mathrm{MPa}$ and $f_{y}=400 \mathrm{MPa}$. Two values of friction coefficient are considered to account for 418 smooth surfaces $(\mu=0.4)$ and intentionally roughened surfaces with sandblasting $(\mu=1.0)$.

\subsection{Slip Strain $(\Delta \varepsilon)$ Distribution}

The slip strain distribution along half the beam span at different load levels for the first jacketing scheme are illustrated in view of Figs. 12(a) and 12(b) for smooth and rough surfaces, respectively. The shown loading values cover the beam onset of jacket yielding, core yielding and ultimate load reached before failure. The slip strain takes its maximum value at mid-span and diminishes as it approaches the supports. The increase in slip strain when the beam is undergoing elastic deformation is proportional to the value of the applied load. This rate of increase changes as yielding of jacket steel reinforcement initiates at beam segments close to the mid-span. This is justified by the reduction in flexural stiffness caused by yielding of these steel bars at these segments. As the load further increases, the slip strain keeps increasing but with a decreasing rate in the segments that exceeded the core yielding point. For the 
431 constant until concrete crushes at the mid-span section. Figs. 12(a) and 12(b) show that as the friction 432 coefficient increases, the slip strain at any segment decreases under the same applied load. This is true 433 because the rougher the surfaces, the higher resistance to relative sliding they will exhibit, and 434 consequently the lower slip strain they will possess. Thus, as the friction coefficient increases, the 435 interfacial behavior approaches the monolithic action assuming full bond between the core and the added 436 concrete layers. The loading values at jacket yield, core yield and ultimate of the three-side jacketed 437 beams are higher than the ones obtained from the former jacketing case due to the larger available 438 concrete area that counteracts the compressive stresses. Despite of these higher loads, the slip strain 439 values along the entire beam are shown to be less than the ones obtained from one side jacketing for the 440 same friction coefficient. This is explained by the larger contact area available between the existing beam 441 and the surrounding jacket that causes a higher increase in frictional resistance that counteracts the 442 relative movement between the two substrates. Hence, increasing the contact area through adopting the 443 U-shape jacket is found to shift the interfacial behavior of the jacketed beams closer to the monolithic 444 action.

\subsection{Slip (S) Distribution}

The slip distribution along the interface for the beam jacketed from one side is presented in Figs. 13(a) and 13(b) for friction coefficient of 0.4 and 1.0, respectively. Due to geometrical and loading symmetry, the distribution is presented along one half the span only. Slip is shown to approach its maximum value at the supports and decreases gradually towards the beam mid-span. The rate of slip increase is constant from the instance the beam is loaded until the steel reinforcement within the jacket are yielded. Beyond this point, the slip rate keeps increasing with an increasing rate due to the yielding 453 of the segments adjacent to the mid-span where the maximum moment is present. Although the beam 
454 failure occurred at a load of $365 \mathrm{kN}$ for both friction coefficients, the maximum slip reached considering 455 smooth surfaces is about $62 \%$ less than the one obtained for the rougher surfaces. Extending the concrete 456 layers around the sides of the beam to form a U-shape results in higher contact area and lower slip values 457 along the interface for the smooth and rough surfaces, respectively. The reduction in maximum slip by 458 increasing the surface roughness is found to be just over $59 \%$ which is very close to the value obtained 459 for the former case. Since the stiffness reduction is directly related to the relative movement activated 460 between the two surfaces, the beams jacketed from three sides exhibit less stiffness reduction than the 461 ones jacketed from one side under the same surface treatment.

\subsection{Interfacial Shear Stress ( $\tau)$ Distribution}

The horizontal shear stress distribution along the interface is directly related to the slip distribution through the stiffness coefficient $\left(k_{s}\right)$. As the slip increases, the secant stiffness coefficient decreases and consequently the calculated shear stress increases but with a decreasing rate as indicated in Figs. 14(a) and 14(b) for smooth and rough surfaces, respectively. Adopting the U-shape jacketing scheme increases the interfacial stiffness coefficient resulting in higher horizontal shear stress resistance for the same slip value. For instance, the maximum slip at ultimate obtained at $\mu=0.4$ for the first case is $0.96 \mathrm{~mm}$ and for the second case is $0.45 \mathrm{~mm}$. However, the corresponding interfacial shear stress is 471 found to be $0.76 \mathrm{MPa}$ and 1.25 MPa for the same cases. This indicates that the stiffness coefficient is about $0.8 \mathrm{~N} / \mathrm{mm}$ for the one side jacketing scheme and $2.8 \mathrm{~N} / \mathrm{mm}$ for the U-shape jacketing configuration at the same load level. This interfacial stiffness variation is justified by the larger contact area and the higher frictional resistance between the two surfaces offered by the three sides jacketing compared to the one side jacketing scheme. Another observation shows that increasing the friction coefficient from 0.4 to 1.0 results in a consequent increase in the maximum slip at ultimate by about $16 \%$ for the first case 
and by $7 \%$ for the second case. This increase results from the increased interfacial frictional resistance

provided by the rougher surface treatment and hence the higher friction coefficient.

\subsection{Plastic Hinge Region}

The formation of a plastic hinge has a detectable influence on the deformation behavior of the

482 examined jacketed beams. The length of the plastic hinge zone $\left(L_{p}\right)$ is defined by the extent of 483 reinforcement yielding within the concrete jacket. The nonlinear material behavior and slip along the 484 interface requires detailed analysis of the jacketed beams. Figure 15(a) illustrates the curvature 485 distribution from the support to the mid-span of beam B-5 corresponding to the ultimate load. It is shown 486 that decreasing the friction coefficient results in reducing the length of the developed plastic hinge. 487 Considering a monolithic interaction between the original beam and the attached jacket, the plastic hinge 488 is found to extend a distance of $582 \mathrm{~mm}$ toward each side from the mid-span. Reducing the friction 489 coefficient to 1.0 and 0.4 results in a consequent reduction of $10.6 \%$ and $21.1 \%$, respectively. This change 490 in behavior is attributed to the stress redistribution that result from the sudden drop in strain at the 491 interface $(\Delta \varepsilon)$ depending on the friction between the two surfaces. For a smaller friction coefficient, $\Delta \varepsilon$ 492 increases causing the strain in the jacket reinforcement to be less than the developed strain in its 493 monolithic counterpart. Figure 15(b) provides further clarification of this observation through plotting 494 the distribution of the strain in the jacket bars from support to the mid-span at ultimate load. The distance 495 from the mid-span to the point on the curve corresponding to yield strain $\left(\varepsilon_{y}=0.002\right)$ represents the 496 plastic hinge region along half the beam span. This zone represents the location where the tensile jacket 497 reinforcement has attained or exceeded its yield value. For the same applied load, decreasing the 498 coefficient of friction reduces the generated strains in the steel bars and consequently results in decreasing 
the extent of the plastic hinge region. The sudden increase in the curvature and stain distribution in Fig.

50015 reflects the onset of yielding of the core reinforcement.

\section{Proposed Expressions for the Monolithic Factors}

The influence of interfacial slip on the flexural behavior of jacketed RC beams is found to have

a reduction in their stiffness especially prior to reaching the core yielding point. Assuming monolithic 505 action in the design of jacketed sections may result in serviceability issues related to excessive deflection and undesirable cracks formation. Including the influence of slip in the analysis is tedious and requires a sequence of nested iterations that may not be convenient for design engineers. Therefore, based on the analytical results conducted on the 20,412 beam specimens, some expressions are developed to plot the actual load-deflection curve of the jacketed beams including slip effects. The difference in loaddeflection behavior between a typical monolithic and partially composite jacketed beams not subjected to initial load prior to strengthening is illustrated in Fig. 16(a). The same information is detailed in Fig.

512 16(b) but taking into consideration the presence of initial load on the overall flexural behavior. The main 513 parameters defining these curves are the jacket yield load $\left(P_{y, J}\right)$ and the corresponding deflections 514 assuming monolithic $\left(\delta_{y, J}\right)$ and partially composite $\left(\delta_{y, J}^{*}\right)$ actions; core yield load $\left(P_{y, c}\right)$ and the 515 corresponding deflections assuming monolithic $\left(\delta_{y, c}\right)$ and partially composite $\left(\delta_{y, c}^{*}\right)$ actions; and ultimate 516 load $\left(P_{u}\right)$ and the corresponding deflections assuming monolithic $\left(\delta_{u}\right)$ and partially composite $\left(\delta_{u}^{*}\right)$ actions. For the initially loaded beams scenario, two additional terms are introduced that define the both

518 the load $\left(P_{\text {initial }}\right)$ and the deflection $\left(\delta_{\text {initial }}\right)$ corresponding to the initial loading value at the onset of 519 jacketing. According to Fig. 16, the monolithic trilinear load-deflection curve of the jacketed beam can 520 be first plotted at three points defined by the jacket yield, core yield and ultimate. Then, the stiffness of 521 each line is reduced indirectly by multiplying the jacket yield deflection, core yield deflection and 
522 ultimate deflection by the jacket yield monolithic factor $\left(\alpha_{y, J}\right)$, core yield monolithic factor $\left(\alpha_{y, c}\right)$ and 523 ultimate monolithic factor $\left(\alpha_{u}\right)$, respectively. Expressions of the aforementioned factors are derived 524 through performing a non-linear regression analysis on the data points and given in Equations 14 and 15 525 in terms of the material mechanical properties, interfacial friction coefficient and the jacketed beam 526 geometrical dimensions.

$$
\begin{aligned}
& \alpha_{i}=\left(A_{1} \xi^{2}+A_{2} \xi+A_{3}\right) \times\left[A_{4} \exp \left(A_{5} \mu\right)\right] \geq 1.0 \\
& \xi=C_{1}+C_{2} \rho+C_{3} f_{c}^{\prime}+C_{4} f_{y}+C_{5} L+C_{6} b_{c}+C_{7} h_{c}+C_{8} h_{J}+C_{9} \frac{\rho f_{y}}{f_{c}^{\prime}}+C_{10} \frac{h_{J}}{h_{c}}+C_{11} \frac{b_{c}}{L}+C_{12} \rho b_{c} h_{c}
\end{aligned}
$$

527 Where $\mu$ is the coefficient of friction, $\rho$ is the steel reinforcement ratio, $f_{c}^{\prime}$ is the concrete compressive 528 strength (MPa), $f_{y}$ is the steel yield strength (MPa), $L$ is the beam span $(\mathrm{m}), b_{c}$ is the original crosssectional width (m), $h_{c}$ is the original cross-sectional height $(\mathrm{m}), h_{J}$ is the jacket thickness (m). The coefficients $\left(A_{i}\right)_{i=1,2,3,4,5}$ and $\left(C_{i}\right)_{i=1,2,3,4,5,6,7,8,9,10,11,12}$ for each monolithic factor (i.e. $\alpha_{y, J}, \alpha_{y, c}$ and $\alpha_{u}$ ) are given in Table 3 as a function of the jacketing scheme.

If the beams were subjected to initial loading before jacketing, then the monolithic factors should 533 be reduced according to the expression given in Equation 16.

$$
\left(\alpha_{i}\right)_{\text {initial }}=\alpha_{i}-\left(\frac{P_{\text {initial }}}{P_{u, \text { unjacketed }}}\right)^{B}\left(\alpha_{i}-1.0\right) \geq 1.0
$$

Where the factor $B$ is taken as $1.432,0.921$ and 0.426 for the jacket yield $\left(\alpha_{y, J}\right)$, core yield $\left(\alpha_{y, J}\right)$ and ultimate $\left(\alpha_{u}\right)$ monolithic factors, respectively.

The expectation function of the proposed monolithic factors is determined considering nonlinear regression analysis of the data. Figs. 17(a) and 17(b) presents the line of equality corresponding to $\alpha_{y, J}$, $538 \alpha_{y, c}$ and $\alpha_{u}$ for both the one-side and three-sides jacketing schemes. The line of equality plots for all factors reveal that the model provides a very good prediction of the actual behavior. The residuals for the 
540 three factors clearly shows a uniformly distributed pattern of the residuals about the mean. The presence

541 of outliers is almost negligible which enhances the confidence of using the proposed expressions.

\section{Conclusions}

An analytical procedure for predicting the flexural behavior of jacketed RC beams is presented

in this paper. The procedure introduces the influence of interfacial slip between the original substrate and 546 the added concrete layer on the moment-curvature and load-deflection relationships. Sectional analysis 547 methodology is extended in the current research to consider the nonlinear properties of both the core and 548 jacket layers simultaneously. The model is validated against relevant experimental results in literature and found to have very good agreement in terms of load-deflection relationship and maximum interfacial slip. Although the proposed model is applicable for beams subjected to uniform loads, literature lacks experimental results related to such loading condition and additional experimental work is required for

552 further validation. Several parameters including material mechanical properties, steel reinforcement 553 ratio, surface treatment conditions, beam span and its cross-sectional dimensions are considered in a 554 parametric study. The parametric analysis encompasses a total of 20,412 beams jacketed from either one 555 side or three sides. Flexural mode of failure is observed in all of the examined specimens regardless of 556 the considered friction coefficient. Investigation of the aforementioned parameters has led to a 557 comprehensive assessment of their significance as well as full description of the developed slip and shear stress distribution. The effect of moment-shear interaction and the development of plastic hinges in the 559 jacketed beams were highlighted. More comprehensive discussion will be provided in a future paper. 560 The parametric study culminated in proposing slip modification factors that can be manipulated by 561 engineers to accurately plot the load-deflection curves of jacketed RC beams taking into account slip 562 impact. 
563 Table 1

564 Geometry of the Discussed Jacketed Beams

\begin{tabular}{cccccc}
\hline Section & $L(\mathrm{~m})$ & $b_{c}(\mathrm{~mm})$ & $h_{c}(\mathrm{~mm})$ & $h_{J}(\mathrm{~mm})$ & Studied Variables \\
\hline B-1 & 3 & 200 & 300 & 100 & $h_{J}, f_{c}^{\prime}, f_{y}$ \\
B-2 & 3 & 200 & 300 & 150 & $h J$ \\
B-3 & 3 & 200 & 300 & 200 & $b_{c}, h_{c}, h_{J}, L$ \\
B-5 & 3 & 200 & 450 & 150 & $\Delta \varepsilon, S, \tau, L_{p}$ \\
B-6 & 3 & 200 & 450 & 200 & $h_{c}$ \\
B-9 & 3 & 200 & 600 & 200 & $h_{c}$ \\
B-12 & 3 & 300 & 300 & 200 & $b_{c}$ \\
B-21 & 3 & 400 & 300 & 200 & $b_{c}$ \\
B-30 & 4 & 200 & 300 & 200 & $L$ \\
B-57 & 5 & 200 & 300 & 200 & $L$ \\
\hline
\end{tabular}

565

566

567 Table 2

568 Description of the Examined Experimental Studies

\begin{tabular}{|c|c|c|c|c|c|c|c|c|c|c|c|}
\hline \multirow[t]{2}{*}{ Reference } & \multirow[t]{2}{*}{ Beam } & \multirow[t]{2}{*}{$\begin{array}{l}\text { Jacketing } \\
\text { Scheme }\end{array}$} & \multicolumn{4}{|c|}{$\begin{array}{c}\text { Geometrical Properties } \\
(\mathbf{m m})\end{array}$} & \multicolumn{2}{|c|}{$\begin{array}{c}\text { Mechanical } \\
\text { Properties (MPa) } \\
\end{array}$} & \multicolumn{3}{|c|}{ Percent Error (\%) } \\
\hline & & & $L$ & $b_{c}$ & $h_{c}$ & $h_{J}$ & $f_{c}^{\prime} / f_{c J}^{\prime}$ & $f_{y}$ & Yield & Ultimate & Stiffness \\
\hline \multirow{2}{*}{$\begin{array}{l}\text { Chalioris } \\
\text { and } \\
\text { Pourzitidis } \\
{[1]}\end{array}$} & B2-J & 3 Sides & 1400 & 125 & 200 & 25 & $28.2 / 42.8$ & $\begin{array}{l}250 / \varphi 5 \\
580 / \varphi 8\end{array}$ & 2.9 & 3.6 & 4.1 \\
\hline & B4-J & 3 Sides & 1400 & 125 & 200 & 25 & $23.4 / 40.0$ & $\begin{array}{l}250 / \varphi 5 \\
580 / \varphi 8\end{array}$ & 7.6 & 7.5 & 5.3 \\
\hline $\begin{array}{l}\text { Chalioris et } \\
\text { al. [2] }\end{array}$ & B1-M & 3 Sides & 1400 & 125 & 200 & 25 & $25.6 / 40.1$ & $\begin{array}{l}255 / \varphi 5 \\
570 / \varphi 8\end{array}$ & 13.4 & 8.6 & 19.2 \\
\hline $\begin{array}{l}\text { Martinola } \\
\text { et al. }[3]\end{array}$ & HPFRC & 3 Sides & 4350 & 300 & 500 & 40 & $22 / 147$ & 560 & 4.3 & 1.7 & 4.1 \\
\hline \multirow{3}{*}{$\begin{array}{l}\text { Hussein et } \\
\text { al. [4] }\end{array}$} & B-U-0 & 1 Side & 1500 & 200 & 200 & 50 & $25 / 111$ & 437 & 5.5 & 3.4 & 3.4 \\
\hline & B-U-1 & 1 Side & 1500 & 200 & 200 & 50 & $25 / 111$ & 437 & 6.5 & 4.7 & 5.3 \\
\hline & B-U-2 & 1 Side & 1500 & 200 & 200 & 50 & $25 / 111$ & 437 & 3.5 & 2.2 & 6.2 \\
\hline Shehata et & V2A & 1 Side & 4000 & 150 & 400 & 150 & $38.6 / 32$ & 500 & 3.7 & 4.3 & 7.3 \\
\hline al. $[5]$ & V3A & 1 Side & 4000 & 150 & 400 & 150 & $39.2 / 32$ & 500 & 1.9 & 2.4 & 5.9 \\
\hline
\end{tabular}


$570 \quad$ Table 3

571 Coefficients Used to Calculate $\alpha_{y, J}, \alpha_{y, c}$ and $\alpha_{u}$ in Equations 14 and 15

\begin{tabular}{|c|c|c|c|c|c|c|}
\hline & \multicolumn{6}{|c|}{ Jacketing Scheme } \\
\hline & \multicolumn{3}{|c|}{ One-Side (Bottom) } & \multicolumn{3}{|c|}{ Three-Sides (U Shape) } \\
\hline & $\alpha_{y, J}$ & $\alpha_{y, c}$ & $\alpha_{u}$ & $\alpha_{y, J}$ & $\alpha_{y, c}$ & $\alpha_{u}$ \\
\hline$A_{1}$ & 2.6899961649 & 36.96861446 & 41.981867551 & 4.438599382 & 75.725029793 & 82.439153754 \\
\hline$A_{2}$ & -5.134946995 & -73.83647068 & -83.92806393 & -8.333525868 & -151.3706306 & -164.8292489 \\
\hline$A_{3}$ & 3.479735767 & 37.870955816 & 42.948454867 & 4.9037982627 & 76.647175373 & 83.391236967 \\
\hline$A_{4}$ & 1.6286381500 & 1.9235439146 & 2.1064756518 & 2.3942208560 & 2.2535194858 & 1.9741828085 \\
\hline$A_{5}$ & -1.200125896 & -1.602941595 & -1.905764829 & -2.332570206 & -2.370423110 & -2.453134776 \\
\hline$C_{1}$ & 1.47472 & 1.03673 & 1.00242 & 1.15853 & 1.0183 & 1.00177 \\
\hline$C_{2}$ & 10.0270 & 0.17240 & -0.08430 & 2.58620 & 0.1083 & 0.06280 \\
\hline$C_{3}$ & -0.0005273 & 0.0003043 & 0.0004479 & -0.0002683 & 0.0001383 & 0.00018642 \\
\hline$C_{4}$ & 0.0000482 & -0.00001012 & -0.00001189 & 0.00001066 & -0.00000385 & -0.00000425 \\
\hline$C_{5}$ & -0.1175 & -0.01127 & -0.00881 & -0.03016 & -0.0056 & -0.00461 \\
\hline$C_{6}$ & 0.49459 & 0.04989 & 0.03798 & -0.01821 & 0.0241 & 0.02229 \\
\hline$C_{7}$ & 0.03576 & 0.00143 & 0.01821 & -0.01393 & 0.0004 & 0.0109 \\
\hline$C_{8}$ & 0.93104 & 0.0881 & 0.06117 & 0.35399 & 0.04704 & 0.02744 \\
\hline$C_{9}$ & -0.13484 & 0.03868 & 0.10403 & -0.03108 & 0.01634 & 0.045543 \\
\hline$C_{10}$ & -0.09899 & 0.005892 & 0.021324 & -0.04814 & 0.002406 & 0.01155 \\
\hline$C_{11}$ & -3.0016 & -0.29909 & -0.18542 & -0.4079 & -0.14899 & -0.10340 \\
\hline$C_{12}$ & -17.54 & -1.22 & -3.08 & -1.44 & -0.50 & -1.70 \\
\hline
\end{tabular}




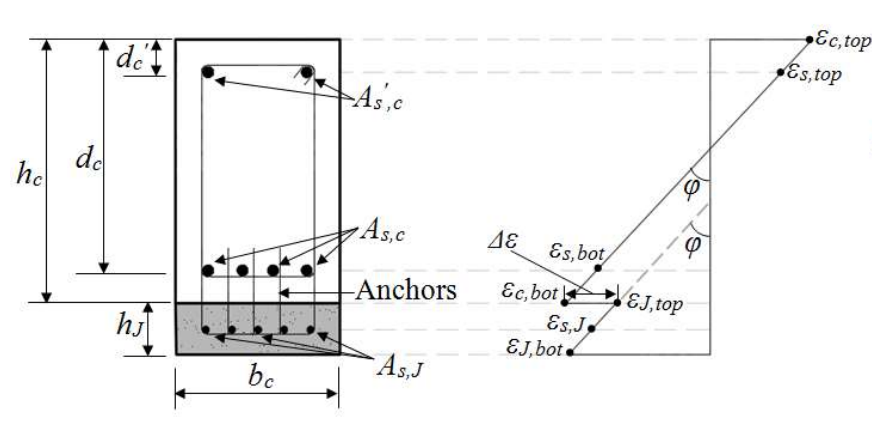

(a)

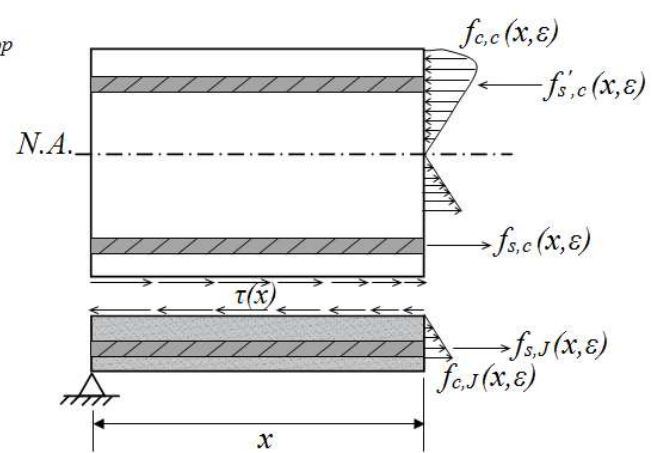

(c)
573 574 575 576

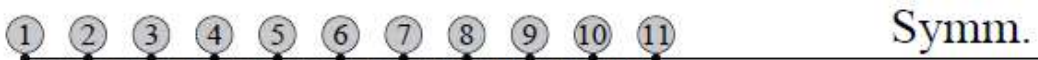

of the beam jacketed from 1 side

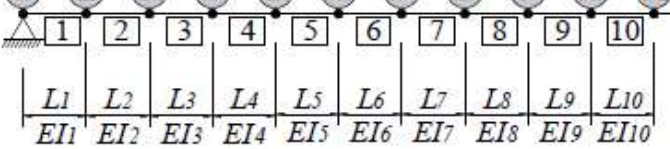

Fig. 3. Definition of jacketed beam segments

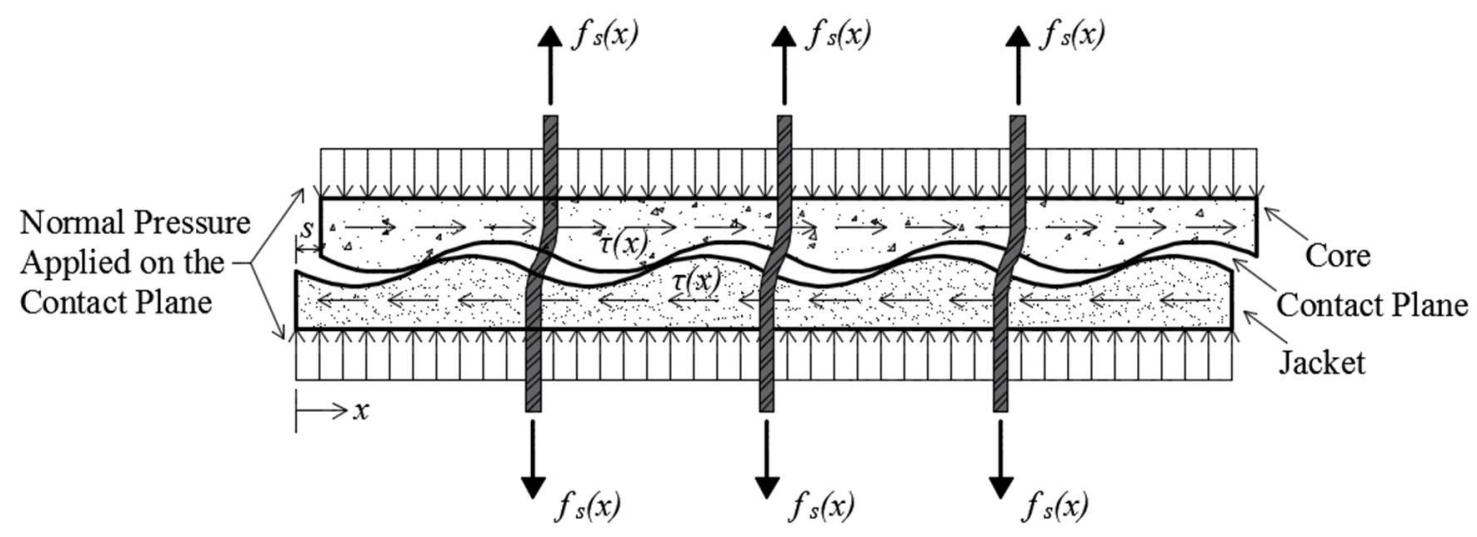

Fig. 2. Interfacial slip model 


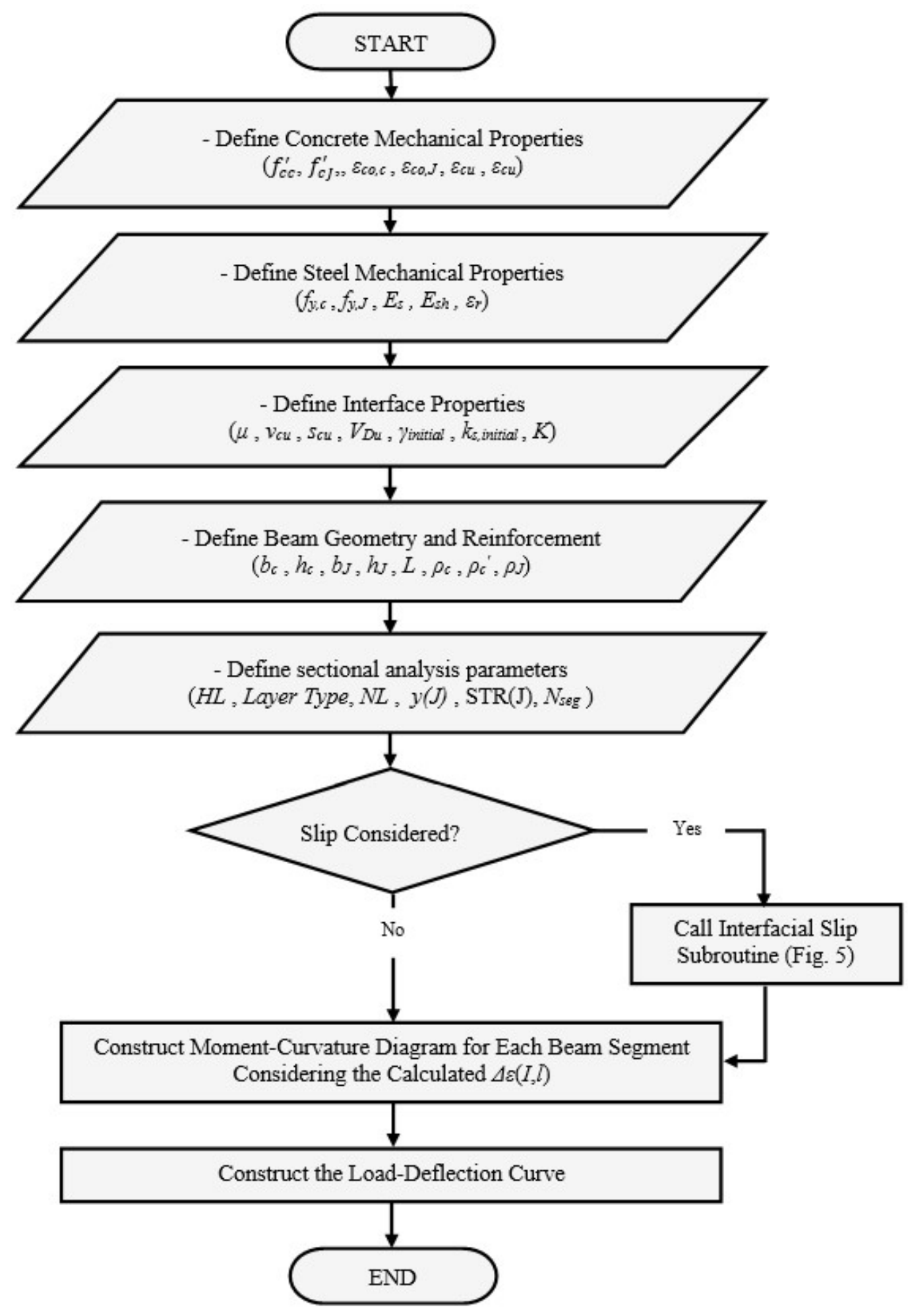

Fig. 4. Flowchart showing the calculation algorithm to analyze jacketed beams 


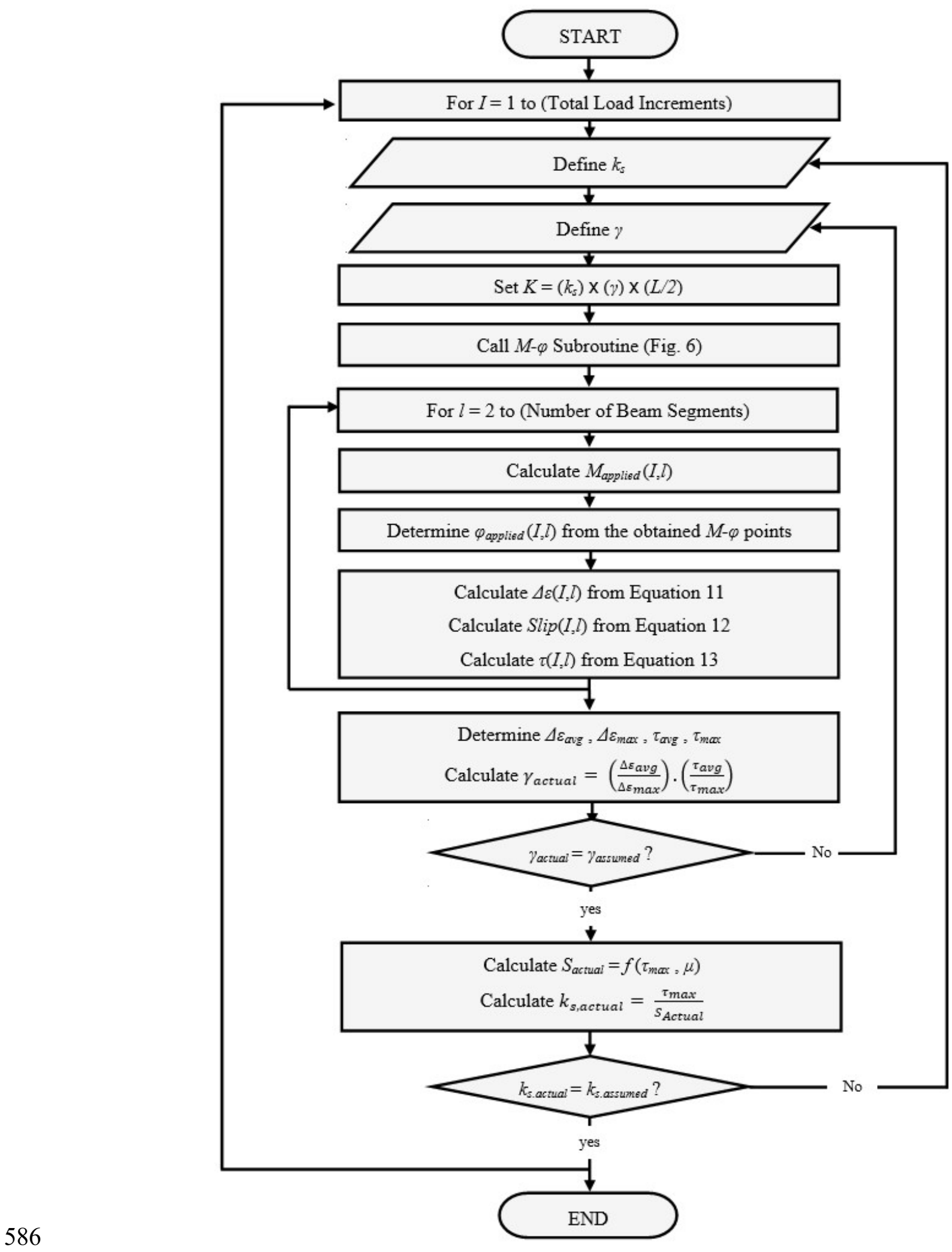

Fig. 5. Interfacial slip calculation subroutine 


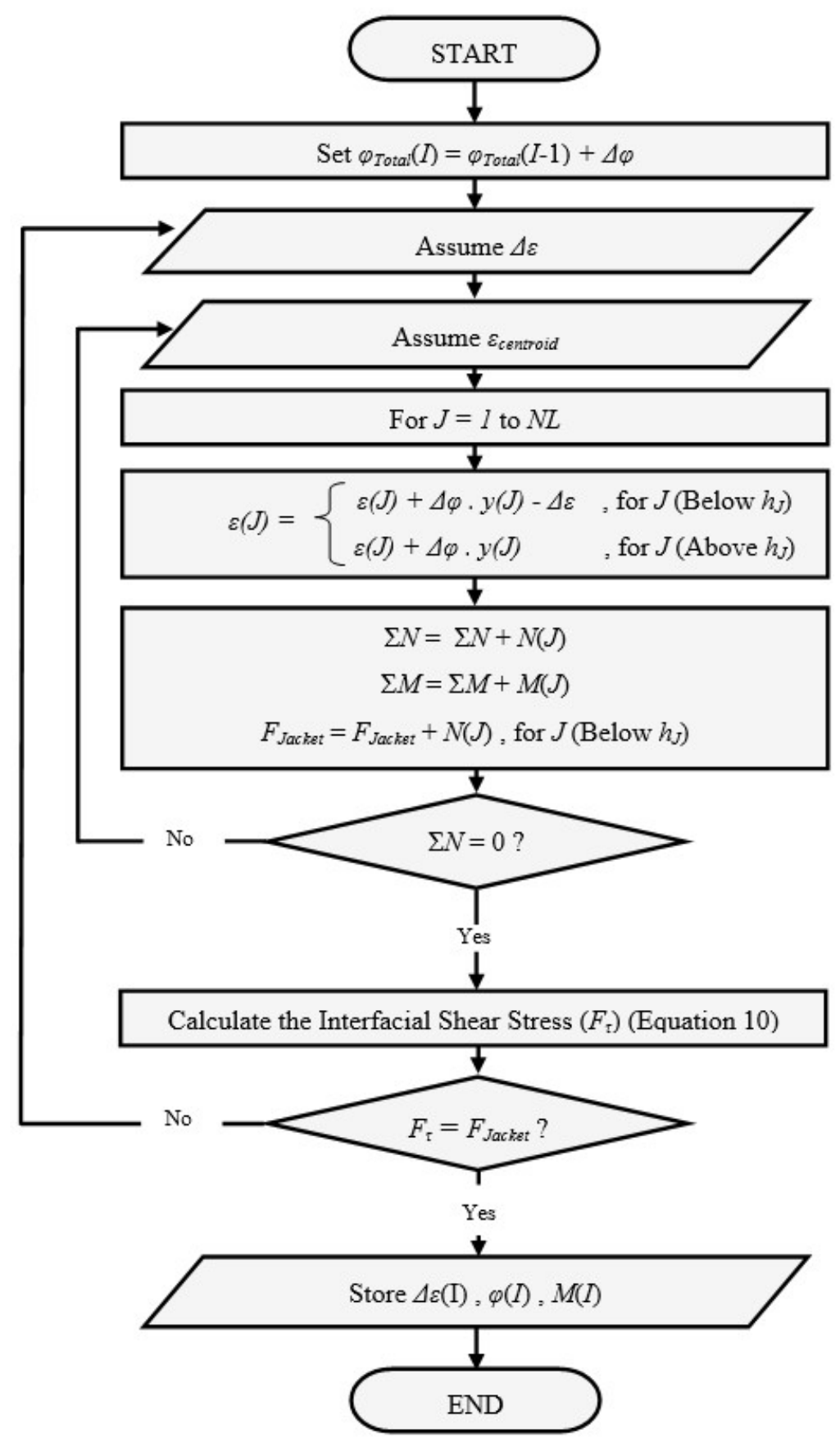

Fig. 6. Moment-curvature $(M-\varphi)$ subroutine 


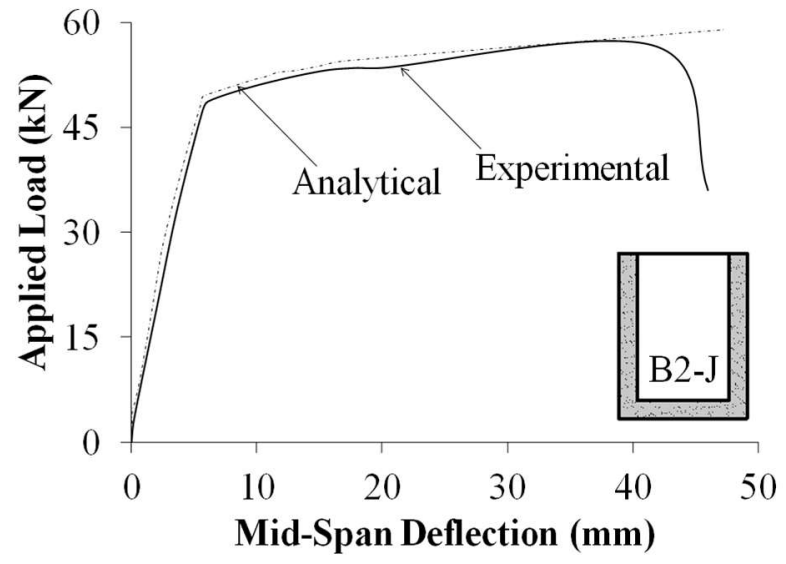

(a) Beam B2-J (Chalioris and Pourzitidis [1])

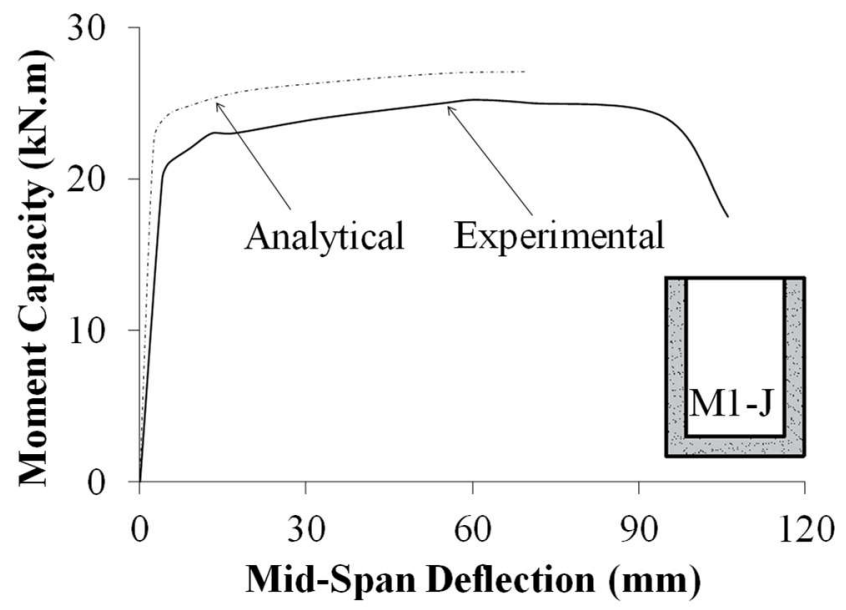

(c) Beam B1-M (Chalioris et al. [2])

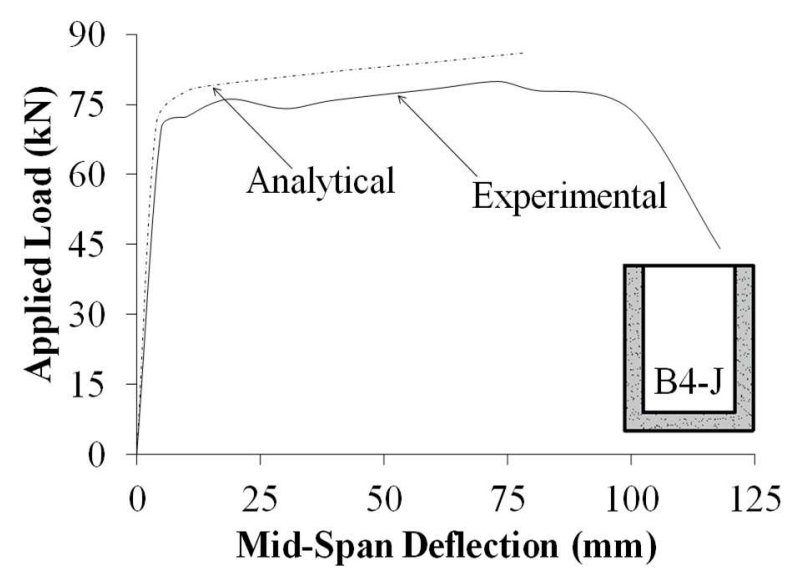

(b) Beam B4-J (Chalioris and Pourzitidis [1])

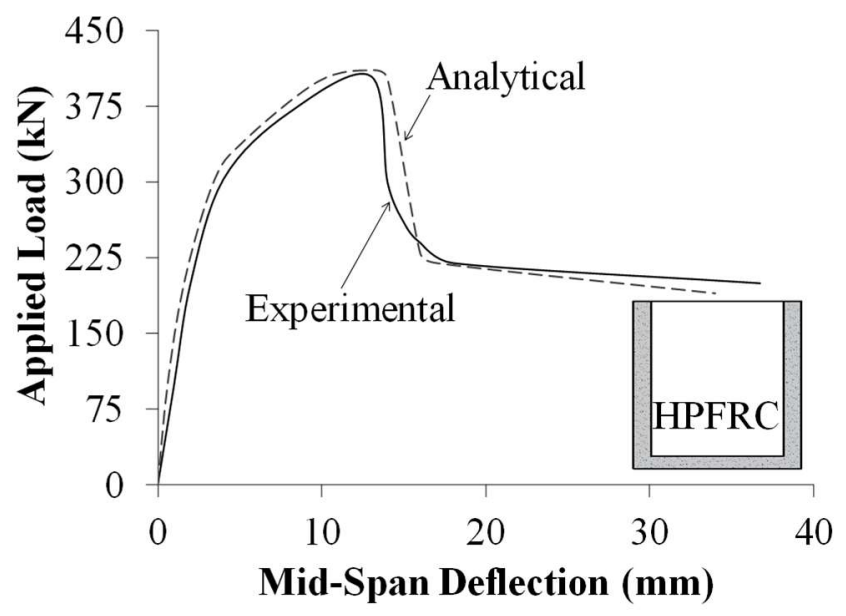

(d) HPFRC (Martinola et al. [3])

Fig. 7. Validation of the proposed analytical model 


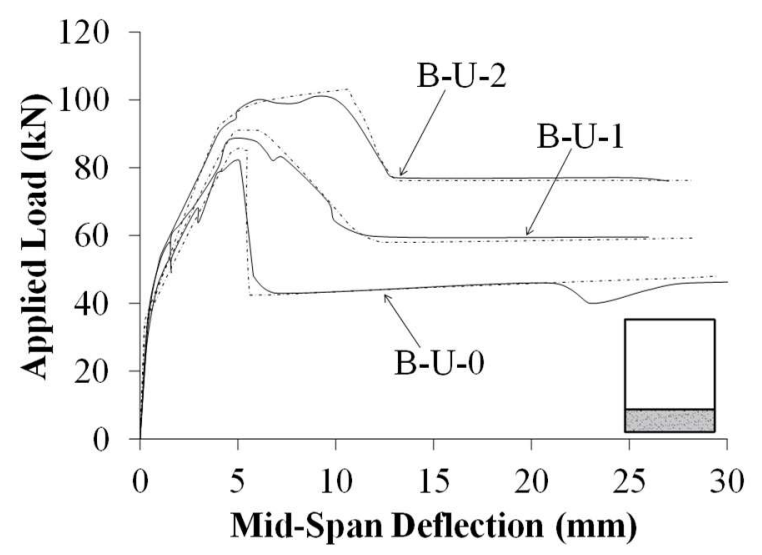

(a) Deformation of B-U-0, B-U-1 and B-U-2

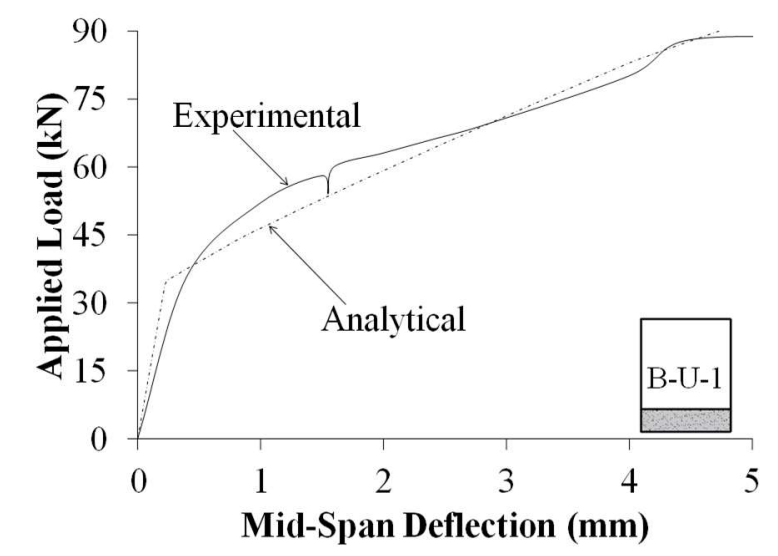

(c) Closer look into the elastic region (B-U-1)

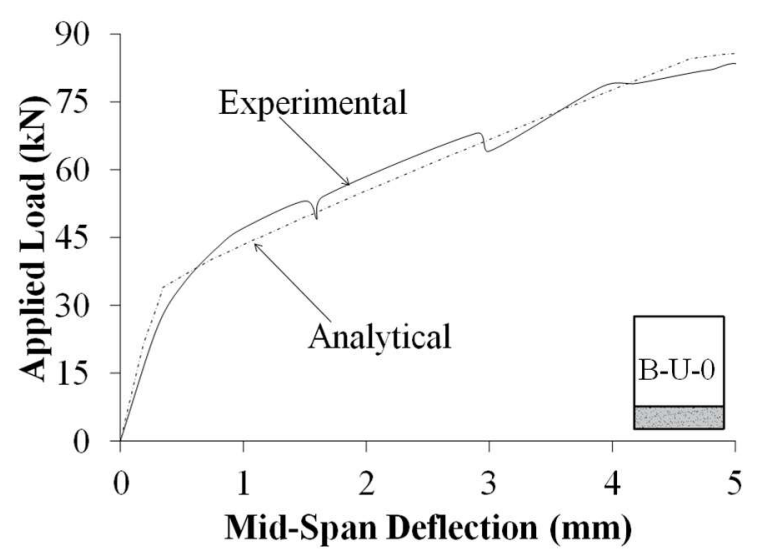

(b) Closer look into the elastic region (B-U-0)

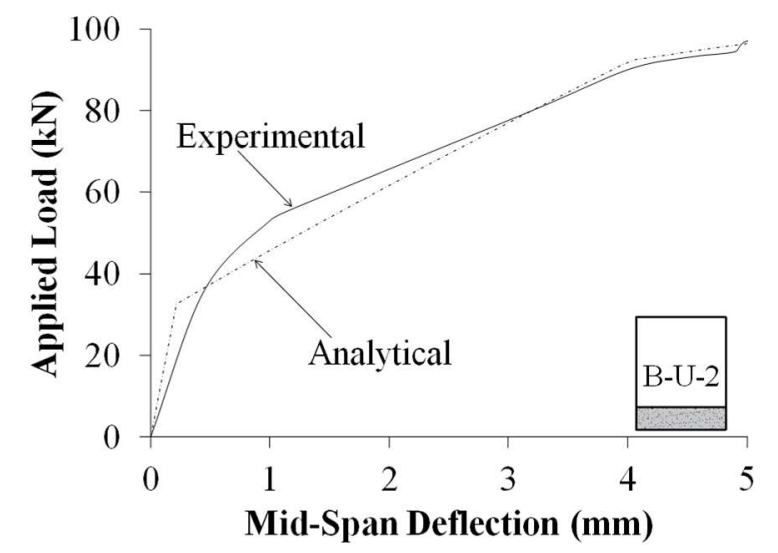

(d) Closer look into the elastic region (B-U-2)

Fig. 8. Validation of the analytical model (Hussein et al. [4])

594

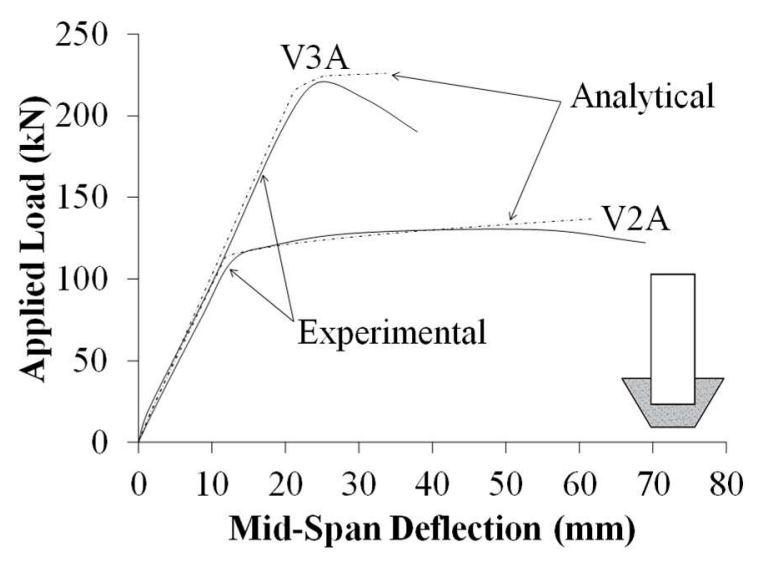

(a) Load-deflection curve of V2A and V3A

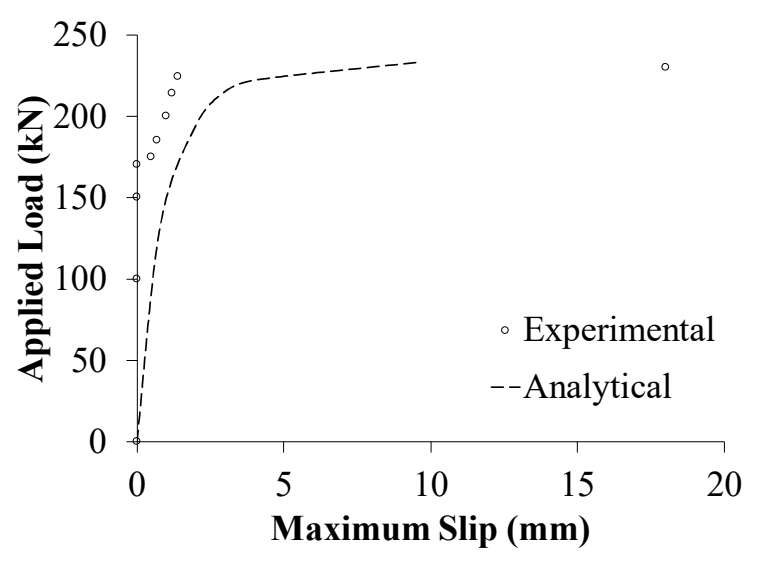

(b) Maximum slip of V3A

Fig. 9. Validation of the analytical model (Shehata et al. [5]) 


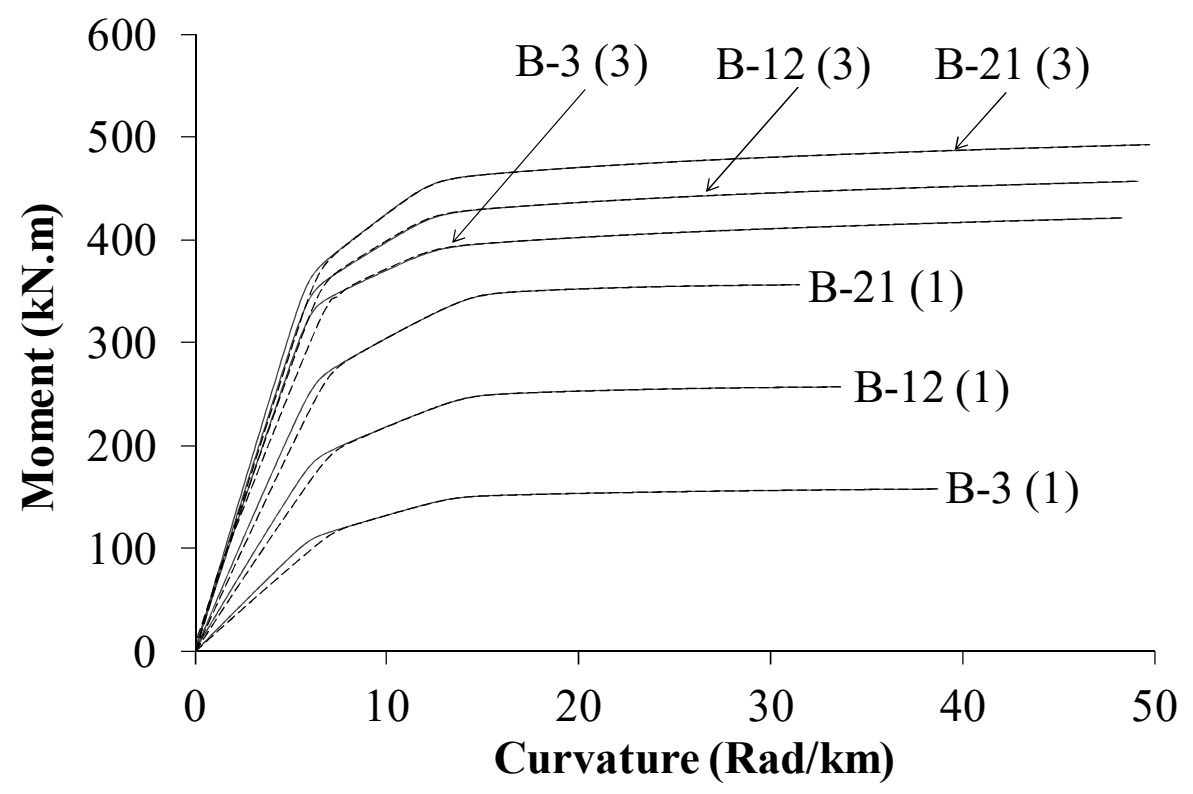

597

Fig. 10. Effect of varying $b_{c}$ on the $M-\varphi$ relationship

598

599

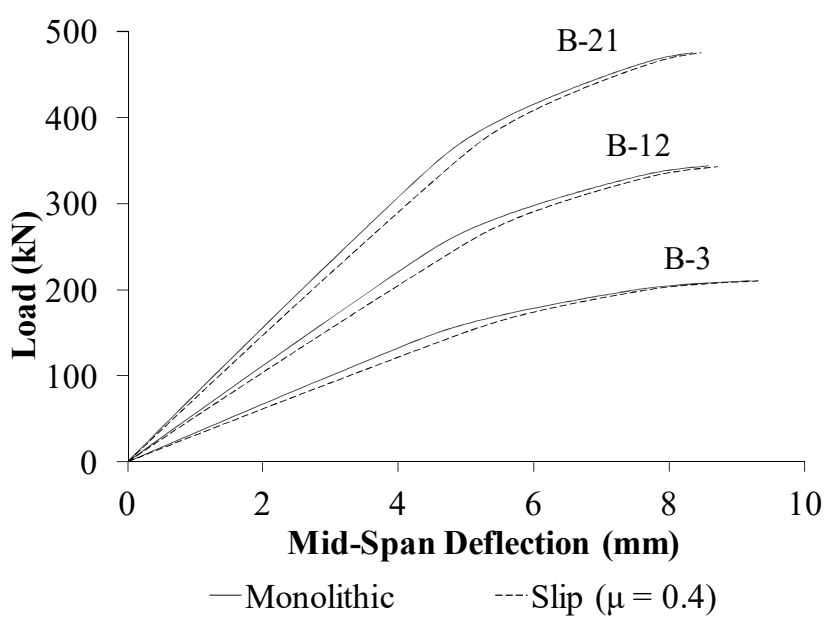

(a) No initial load

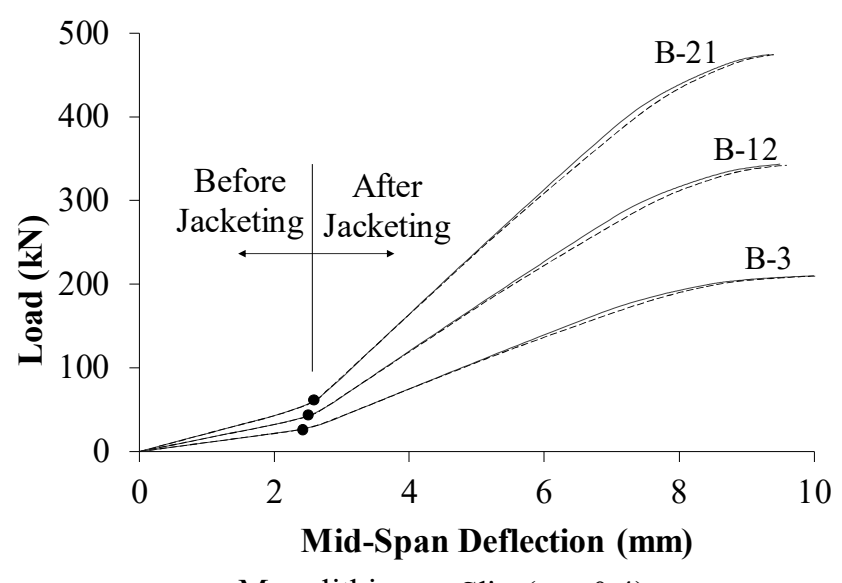

-Monolithic $\quad-$ Slip $(\mu=0.4)$

Fig. 11. Effect of varying $b_{c}$ on the $P-\Delta$ relationship jacketed along one side 


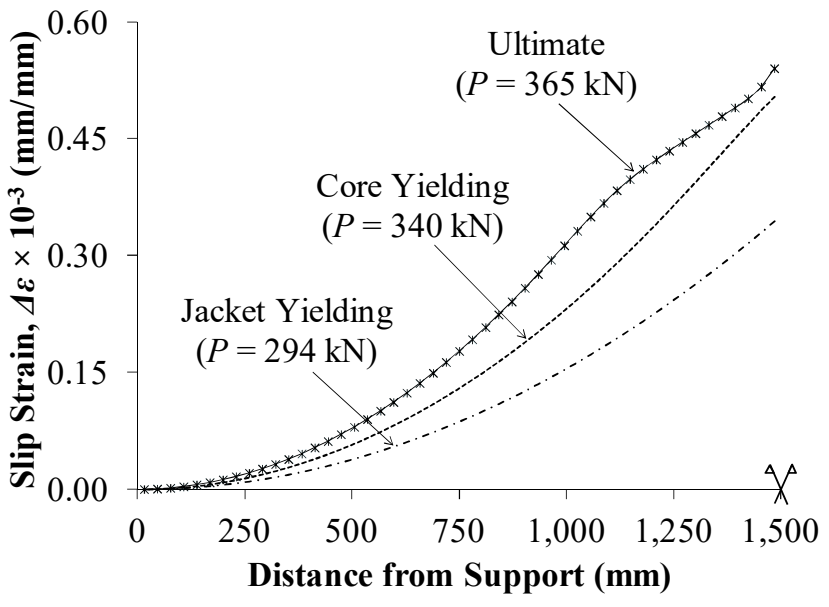

(a) $\mu=0.4$

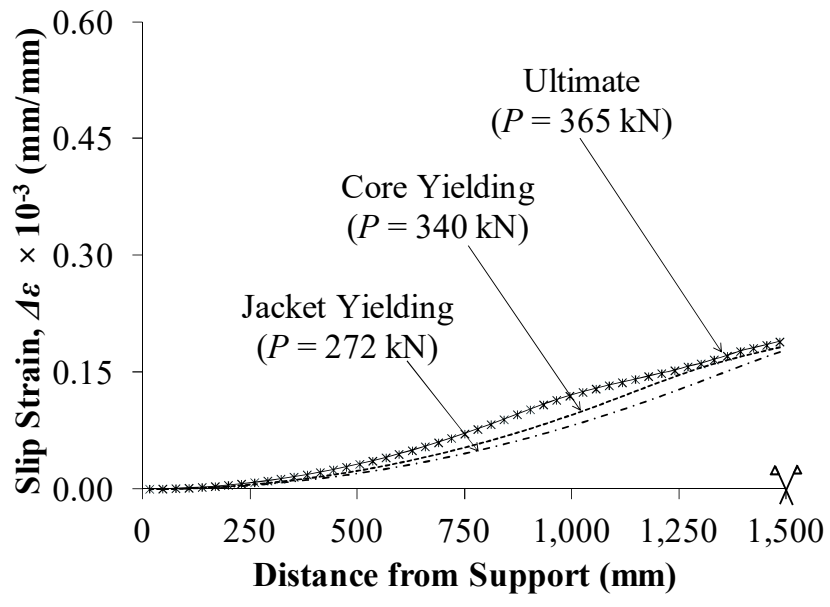

(b) $\mu=1.0$

Fig. 12. Slip strain $(\Delta \varepsilon)$ distribution along beam B-5 jacketed along one side

602

603

604

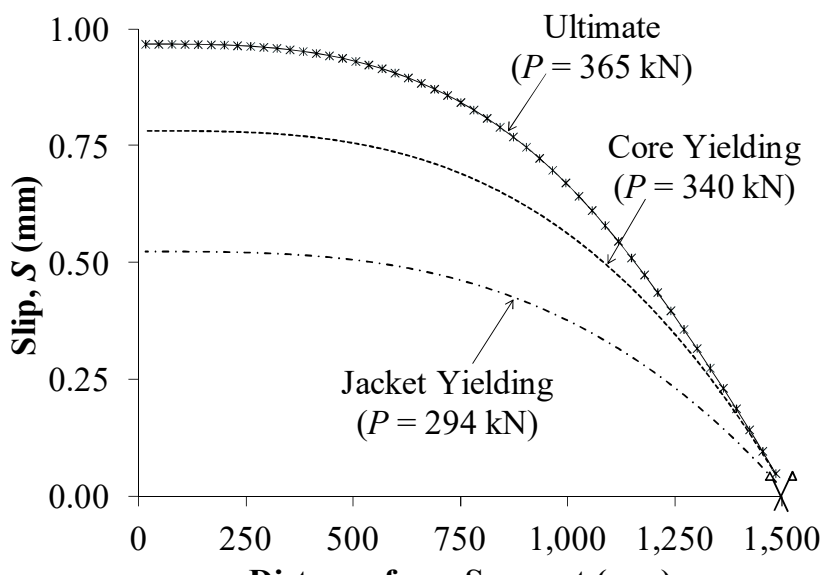

Distance from Support (mm)

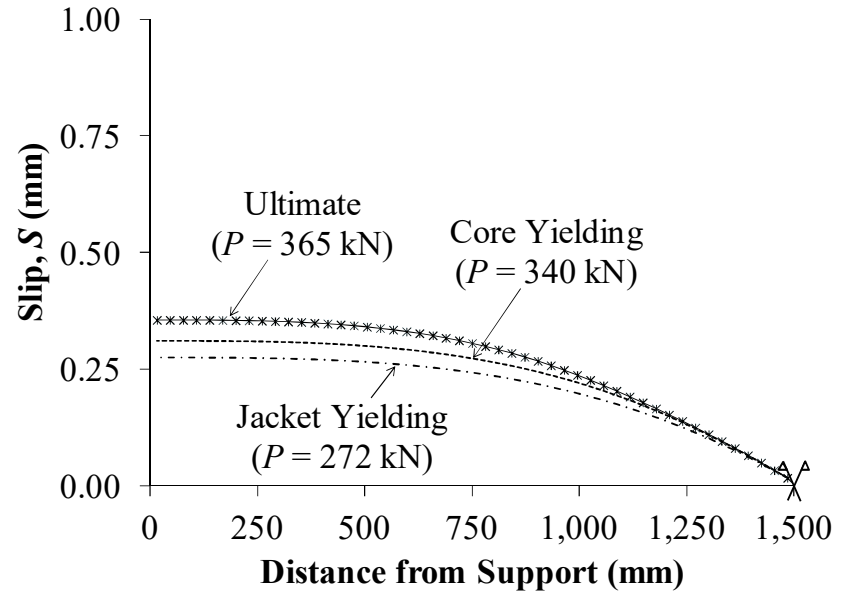

(b) $\mu=1.0$

Fig. 13. Slip distribution $(S)$ along beam B-5 jacketed from one side

606

607

608

609 


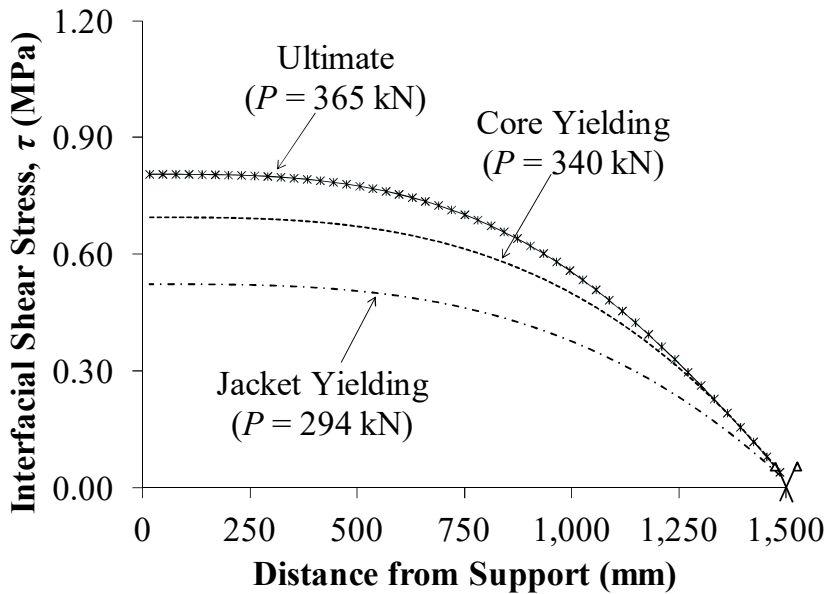

(a) $\mu=0.4$

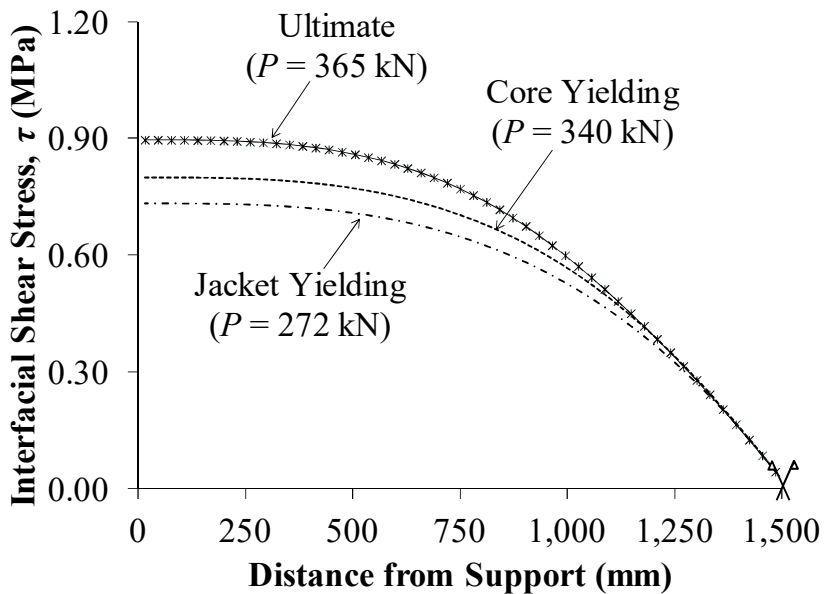

(b) $\mu=1.0$

610

Fig. 14. Interfacial shear stress distribution $(\tau)$ along beam B-5 from one side

611

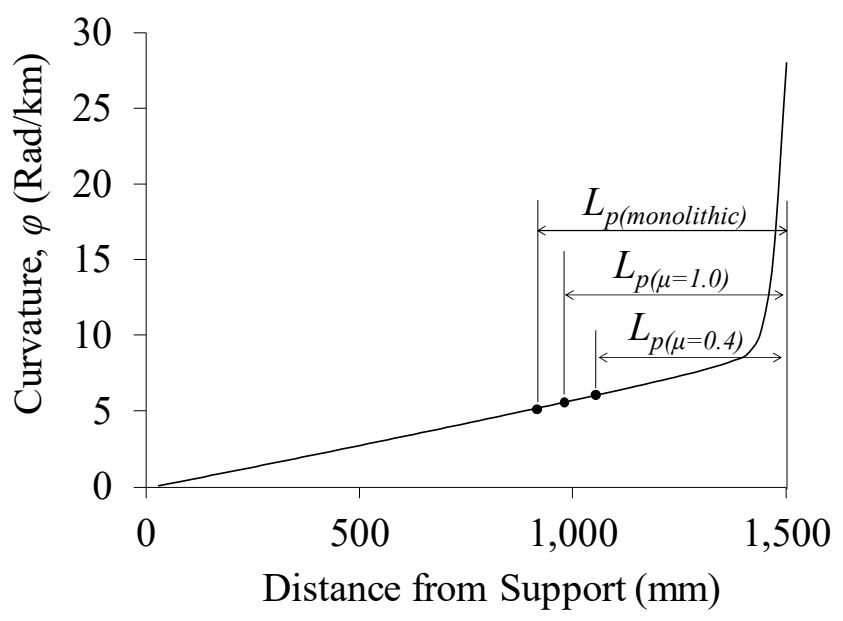

(a) Strain distribution in jacket reinforcement

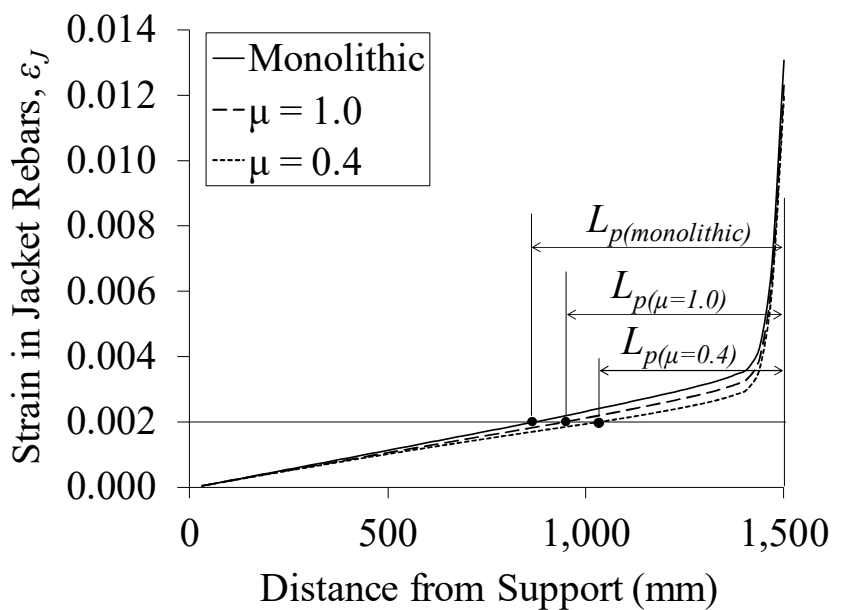

(b) Strain distribution in jacket reinforcement 


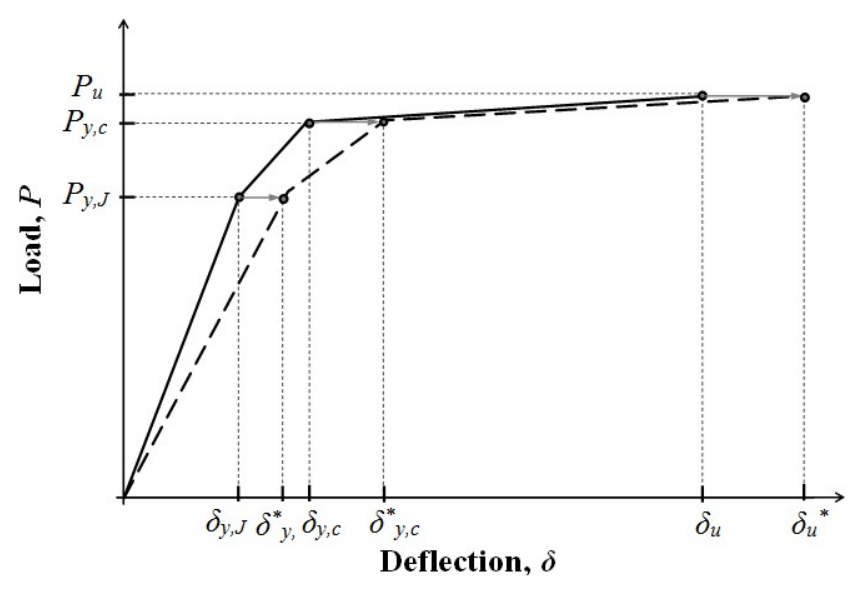

(a) No initial load

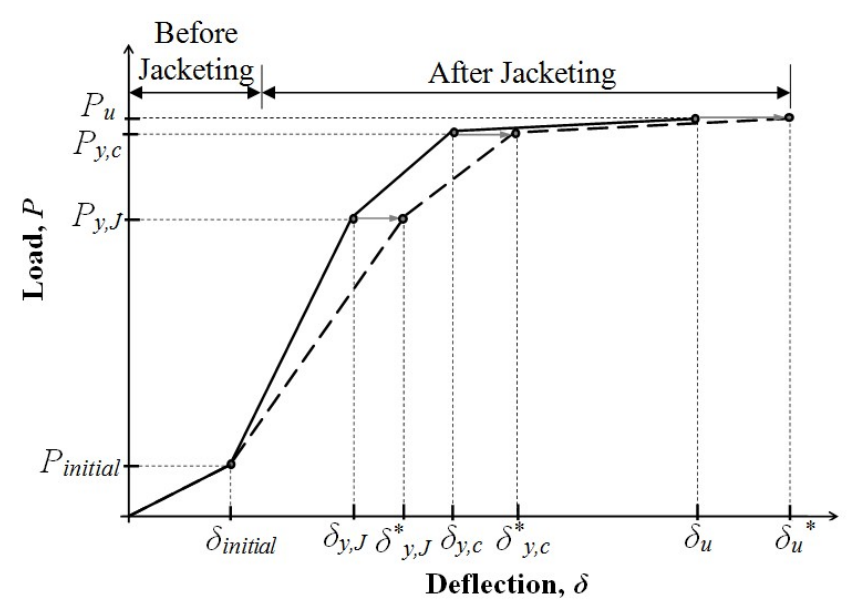

(b) With initial load

Fig. 16. Stiffness reduction model for a typical jacketed beam

616

617

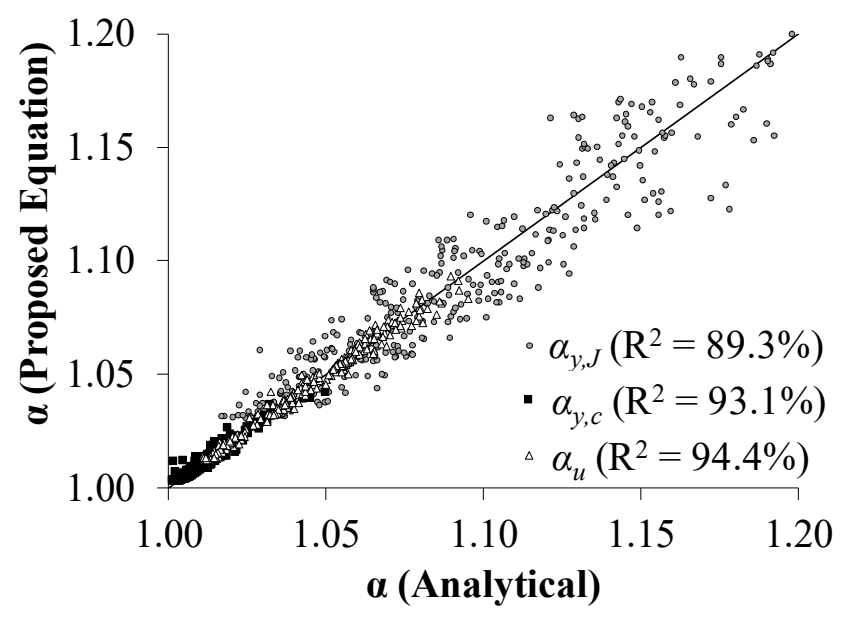

(a) Jacketing from one side

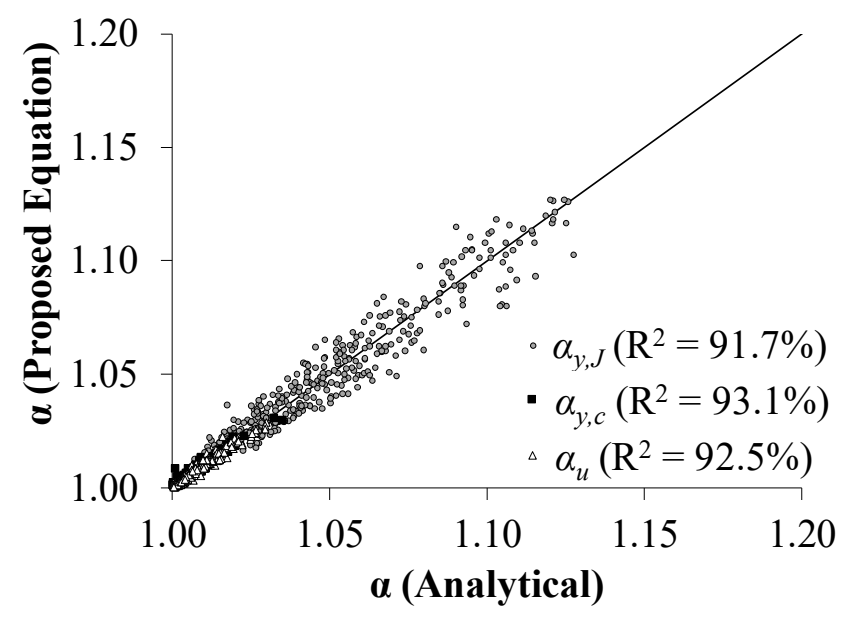

(b) Jacketing from three sides 


\section{Appendix}

622

623 Sample calculation of the proposed analytical model and the flowcharts in Figs. 4 through 6 considering 624 beam B-3 defined in Table 1.

625

626 1- Define the Inputs:

627 Concrete properties: $f_{c c}^{\prime}=30 \mathrm{MPa}, f_{c J}^{\prime}=30 \mathrm{MPa}, \varepsilon_{c o, c}=0.002, \varepsilon_{c o, J}=0.002, \varepsilon_{c u}=0.0035$

628 Steel properties: $f_{y c}=400 \mathrm{MPa}, f_{y J}=400 \mathrm{MPa}, E_{s}=200 \mathrm{GPa}, E_{s h}=2 \mathrm{GPa}, \varepsilon_{r}=0.2$

629 Beam geometry: $b_{c}=200 \mathrm{~mm}, h_{c}=300 \mathrm{~mm}, b_{J}=200 \mathrm{~mm}, h_{J}=200 \mathrm{~mm}, L=3 \mathrm{~m}$

630 Reinforcement: $\rho_{c}=0.5 \rho_{\text {balance }}=0.5 \times 0.0263=0.01315, A_{s, J}=A_{\text {bar }} \times S_{\max }=100 \times 15.8=158 \mathrm{~mm}$

631 Sectional analysis parameters: $H L=2 \mathrm{~mm}, N L=250, N_{\text {seg }}=60$

632 Slip coefficients: $\mu=0.4, k_{s}=1.0 \mathrm{~N} / \mathrm{mm}^{3}$ (Assumed), $\gamma=0.3$ (Assumed), $K=450 \mathrm{MPa}$ (Equation 8).

633

634 2-Calculate the (moment-curvature) and (moment-slip strain) curves at the mid-span section:

635

Sample point at load increment 5: $M_{\max }=3,906,586$ N.mm, $\varphi=0.4 \times 10^{-6}, \Delta \varepsilon_{\max }=2.80 \times 10^{-5}, F_{\tau}=F_{\text {Jacket }}$ 636

3-Calculate the (moment-curvature) and (moment-slip strain) curves at all other segments:

638 The moment distribution along the beam depends on the applied load. For this example, assume a 639 concentrated load at beam mid-span. The load $(P)$ points corresponding to all moment values in the $M_{\max }{ }^{-}$ $640 \varphi$ diagram obtained from step 2 are calculated as $P_{\max }=4 M_{\max } / L=4 \times 3,906,586 / 3000=5,208 \mathrm{~N}$. Then,

641 the moment and the corresponding curvature at each beam segment are determined. At the same load 642 increment for beam segment number 10 located at a distance of $500 \mathrm{~mm}$ from mid-span:

$M_{(5,10)}=1,302,000$ N.mm, $\varphi_{(5,10)}=0.136 \times 10^{-6}, \Delta \varepsilon_{(5,10)}=3.24 \times 10^{-6}$ 
644 4-Calculate the maximum and average and maximum (slip strain) and (shear stress) along the beam:

$645 \Delta \varepsilon_{\max }=2.80 \times 10^{-5}, \Delta \varepsilon_{\text {avg }}=9.52 \times 10^{-6}, \tau_{\max }=0.0142 \mathrm{MPa}, \tau_{\text {avg }}=0.0108 \mathrm{MPa}$

646

647 5-Calculate Yactual and compare it to Yassumed:

$648 \gamma_{\text {actual }}=\left(\Delta \varepsilon_{\text {avg }} / \Delta \varepsilon_{\max }\right) \times\left(\tau_{\text {avg }} / \tau_{\max }\right)=0.258<\left(\gamma_{\text {assumed }}=0.3\right)$

649 Therefore, repeat the same procedure until $\gamma_{\text {actual }}=\gamma_{\text {assumed }}$. After many iterations, the values of the

650 parameters become: $\Delta \varepsilon_{\max }=3.10 \times 10^{-5}, \Delta \varepsilon_{\text {avg }}=1.07 \times 10^{-5}, \tau_{\max }=0.0161 \mathrm{MPa}, \tau_{\text {avg }}=0.0122 \mathrm{MPa}$

651

652 6-Calculate $k_{s, a c t u a l}$ and compare it to $k_{s, a s s u m e d:}$

$653 k_{s, \text { actual }}=3.33 \mathrm{~N} / \mathrm{mm}^{3}>\left(k_{s, \text { assumed }}=1.0 \mathrm{~N} / \mathrm{mm}^{3}\right)$

654 Therefore, repeat the same procedure until $k_{s, a c t u a l}=k_{s, \text { assumed. }}$. After many iterations, the values of the 655 parameters become: $\Delta \varepsilon_{\max }=1.09 \times 10^{-5}, \Delta \varepsilon_{\text {avg }}=3.76 \times 10^{-6}, \tau_{\max }=0.0188 \mathrm{MPa}, \tau_{\text {avg }}=0.0143 \mathrm{MPa}$ 656

657 7- Repeat steps 3 through 6 for all load increments in order to obtain both (moment-curvature) and 658 (moment-slip strain) diagrams for each beam segment.

659

660 8-Construct the load-deflection curve using moment-area theorem with the knowledge of the moment661 curvature diagram of each beam segment.

662 


\section{Nomenclature}

$664 A_{s, c}^{\prime} \quad$ area of the compression core reinforcement $\left(\mathrm{mm}^{2}\right)$

$665 A_{s, c} \quad$ area of the tension core reinforcement $\left(\mathrm{mm}^{2}\right)$

$666 A_{s, J} \quad$ area of the tension jacket reinforcement $\left(\mathrm{mm}^{2}\right)$

$667 \quad b_{c} \quad$ width of the existing beam section $(\mathrm{m})$

$668 \quad D_{b} \quad$ diameter of the steel bars $(\mathrm{mm})$

$669 d_{c} \quad$ effective depth of the tension core reinforcement $(\mathrm{mm})$

$670 d_{c}^{\prime} \quad$ effective depth of the compression core reinforcement (mm)

$671 \quad E_{s} \quad$ elastic modulus of steel $(\mathrm{MPa})$

$672 \quad E_{s h} \quad$ strain hardening modulus of steel (MPa)

$673 f_{c} \quad$ compressive stress of concrete at a given strain $\varepsilon_{c}(\mathrm{MPa})$

$674 f_{c}^{\prime} \quad$ compressive strength of concrete at 28 days (MPa)

$675 f_{s} \quad$ stress developed in steel bars at a given strain $\varepsilon_{s}(\mathrm{MPa})$

$676 f_{s u} \quad$ ultimate strength of steel $(\mathrm{MPa})$

$677 f_{y} \quad$ yield strength of steel $(\mathrm{MPa})$

$678 \quad F_{\tau} \quad$ interfacial shear force $(\mathrm{N})$

$679 h_{c} \quad$ height of the existing beam section (m)

$680 h_{J} \quad$ thickness of the attached concrete jacket (m)

$681 \quad H L \quad$ Layer height used in sectional analysis $(\mathrm{mm})$

$682 \quad K \quad$ global interfacial slip coefficient (MPa)

$683 \quad k_{s} \quad$ secant interfacial stiffness $\left(\mathrm{N} / \mathrm{mm}^{3}\right)$

$684 \quad L \quad$ Beam Span (m)

$685 \quad L_{s} \quad$ Shear Span (m) 


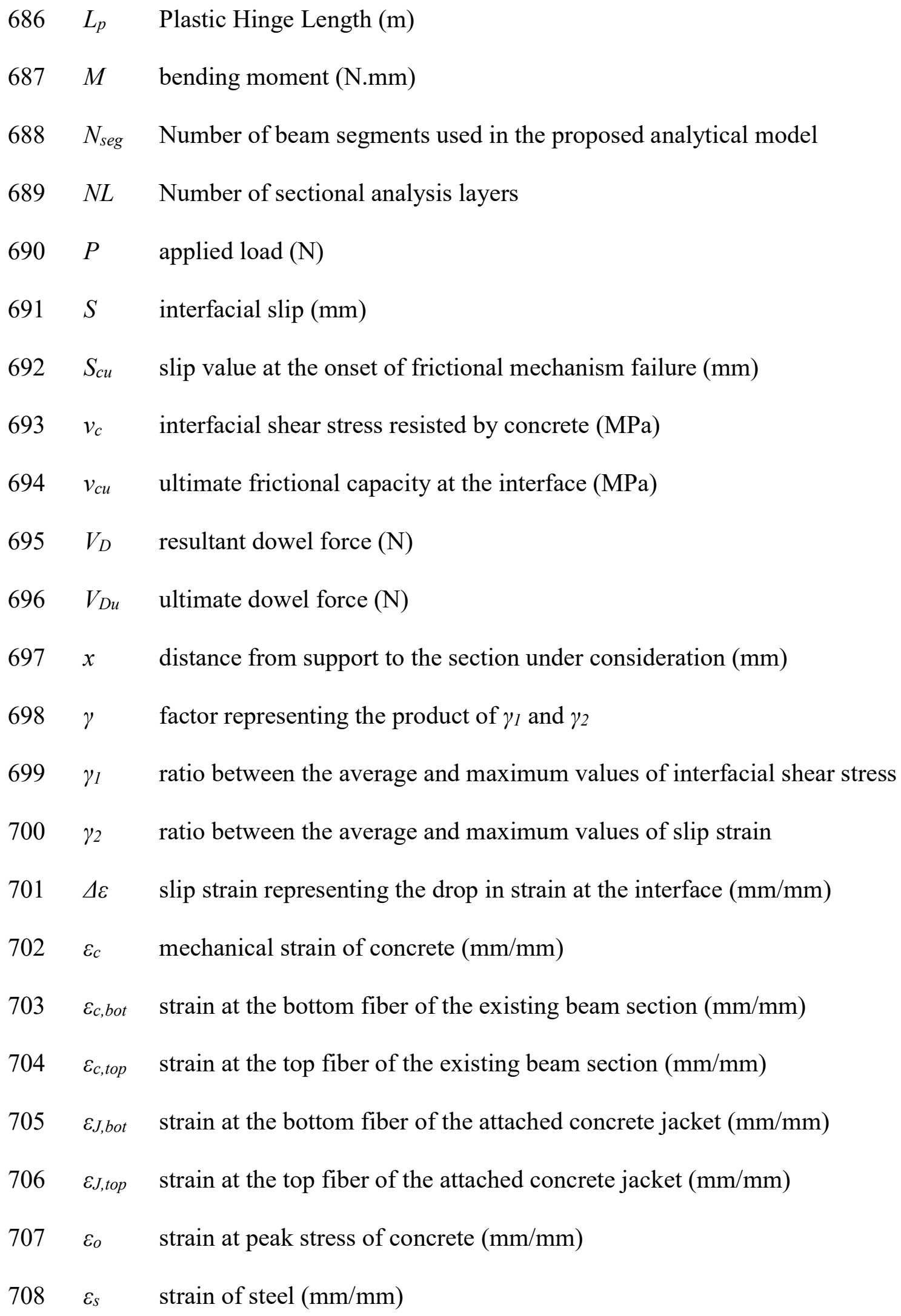




$\begin{array}{lll}709 & \varepsilon_{s, b o t} & \text { strain in the bottom core reinforcement }(\mathrm{mm} / \mathrm{mm}) \\ 710 & \varepsilon_{s, J} & \text { strain in the jacket reinforcement }(\mathrm{mm} / \mathrm{mm}) \\ 711 & \varepsilon_{s, t o p} & \text { strain in the top core reinforcement }(\mathrm{mm} / \mathrm{mm}) \\ 712 & \varepsilon_{s h} & \text { strain hardening strain of steel }(\mathrm{mm} / \mathrm{mm}) \\ 713 & \varepsilon_{u} & \text { strain at ultimate strength of steel }(\mathrm{mm} / \mathrm{mm}) \\ 714 & \varepsilon_{y} & \text { strain at yield strength of steel }(\mathrm{mm} / \mathrm{mm}) \\ 715 & \mu & \text { coefficient of shear friction at the interface } \\ 716 & \rho_{s} & \text { steel reinforcement ratio } \\ 717 & \tau & \text { interfacial shear stress }(\mathrm{MPa}) \\ 718 & \varphi & \text { curvature (rad } / \mathrm{mm})\end{array}$




\section{References}

720

721 [1] Chalioris CE, Pourzitidis CN (2012). Rehabilitation of shear-damaged reinforced concrete beams

722

723

724

725

726

727

728

729

730

731

732

733

734

735

736

737

738

739

740

741 using self-compacting concrete jacketing. International Scholarly Research Notices 2012; Article 816107: 1-12.

[2] Chalioris C, Papadopoulos C, Pourzitidis N, Fotis D, Sideris K. Application of a Reinforced SelfCompacting Concrete Jacket in Damaged Reinforced Concrete Beams under Monotonic and Repeated Loading. J of Eng. 2013; ID 912983: 1-12.

[3] Martinola G, Meda A, Plizzari G, Rinaldi Z. Strengthening and repair of RC beams with fiber reinforced concrete. Cement Concrete Comp 2010; 32(9):731-739.

[4] Hussein M, Kunieda M, Nakamura H. Strength and ductility of RC beams strengthened with steelreinforced strain hardening cementitious composites. Cement Concrete Comp 2012; 34(9):10611066.

[5] Shehata I, Shehata, L, Santos E, Simoes M. Strengthening of Reinforced Concrete Beams in Flexure by Partial Jacketing. Mater Struct 2009; 42(4): 495-504.

[6] Meda A, Plizzari G, Rinaldi Z, Martinola G. Strengthening of R/C existing columns with high performance fiber reinforced concrete jacket. Concrete Repair, Rehabilitation and Retrofitting, 2009, Taylor and Francis Group, London, UK.

[7] Ersoy U, Tankut T, Suleiman R. Behavior of Jacketed Columns. ACI Struct J. 1993; 90(3): 288293.

[8] Ilki A, Demir C, Bedirhanoglu I, Kumbasar N. Seismic retrofit of brittle and low strength RC columns using fiber reinforced polymer and cementitious composites, Adv Struct Eng (2009); 12(3): 325-347. 
742 [9] Bousias S, Spathis A, Fardis M. Seismic retrofitting of columns with lap-spliced smooth bars 743 through FRP or concrete jackets. J EarthQ Eng 2007; 11: 653-674.

744 [10] Bousias S, Spathis A, Fardis M. Seismic retrofitting of columns with lap-splices through CFRP 745 jackets. $13^{\text {th }}$ World Conference on Earthquake Engineering, 2004, Vancouver, B.C., Canada.

746 [11] Santos PMD, Júlio ENBS. A State-of-the-Art Review on Shear-Friction. Eng Struct 2012; 45:435$747 \quad 448$.

748 [12] CSA. Design of concrete structures (CAN/CSA A23.3-14). Cement Association of Canada, $749 \quad$ Ottawa, ON; 2014.

750 [13] ACI Committee 318. Building code requirements for structural concrete and commentary (ACI 751 318-14). American Concrete Institute, Farmington Hills, MI; 2014.

752 [14] Zilch K, Reinecke R. Capacity of shear joints between high-strength precast elements and normal753 strength cast-in-place decks. Proceedings of the International Symposium of High Performance Concrete, Orlando, FL, 2000:551-560.

[15] Tsioulou OT, Dritsos SE. A theoretical model to predict interface slip due to bending. Mater Struct $2011 ; 44: 825-843$.

[16] Scott BD, Park R, Priestley MJN. Stress-Strain Behavior of Concrete Confined by Overlapping Hoops at Low and High Strain Rates. J. of the American Conc. Inst 1982; 79(1): 13-27.

[17] Karthik MM, Mander JB. Stress-block parameters for unconfined and confined concrete based on a unified stress-strain model. J Struct Eng-ASCE 2011; 137(2):270-273.

[18] Ramberg W, Osgood WR. Description of stress-strain curves by three parameters. Technical Note No. 902, National Advisory Committee For Aeronautics, Washington DC, 1943.

[19] Thermou GE, Pantazopoulou SJ, Elnashai AS. Flexural behavior of brittle RC members rehabilitated with concrete jacketing. J Struct Eng-ASCE 2007; 133(10):1373-1384. 
765 [20] Gohnert M. Proposed Theory to Determine the Horizontal Shear between Composite Precast and 766 In-Situ Concrete. Cement Concrete Comp 2000; 22(6):469-476.

767 [21] Abdelouahed T. Improved Theoretical Solution for Interfacial Stresses in Concrete Beams 768 Strengthened with FRP Plate. Int J Solids Struct 2006; 43(14-15): 4154-4174.

769 [22] Tassios T, Vintzeleou E. Concrete-to-Concrete Friction. J Struct Eng-ASCE 1987; 113(4):832-849.

770 [23] Eurocode2. (2004). Design of concrete structures- part 1.1: general rules and rules for buildings.

771 European Committee for Standardization (CEN), Brussels, Belgium; 2004.

772 [24] Youssef MA, Rahman M. Simplified seismic modeling of reinforced concrete flexural members.

773 Mag Concrete Res 2007; 59(9):639-649.

774 [25] Russo G, Zingone G, Puleri G. Flexure-Shear Interaction Model for Longitudinally Reinforced 775 Beams. ACI Struct J 1991; 88(1): 60-68. 